NBER WORKING PAPER SERIES

\title{
THE EFFECT OF CHANGES IN DRUG UTILIZATION ON LABOR SUPPLY AND PER CAPITA OUTPUT
}

\author{
Frank R. Lichtenberg \\ Working Paper 9139 \\ http://www.nber.org/papers/w9139 \\ NATIONAL BUREAU OF ECONOMIC RESEARCH \\ 1050 Massachusetts Avenue \\ Cambridge, MA 02138 \\ September 2002
}

The views expressed in this paper are those of the author and not necessarily those of the National Bureau of Economic Research.

(C) 2002 by Frank R. Lichtenberg. All rights reserved. Short sections of text, not to exceed two paragraphs, may be quoted without explicit permission provided that full credit, including $\mathbb{C}$ notice, is given to the source. 
The Effect of Changes in Drug Utilization on Labor Supply and

Per Capita Output

Frank R. Lichtenberg

NBER Working Paper No. 9139

September 2002

JEL No. J2, O3, I1, L65

\section{$\underline{\text { ABSTRACT }}$}

We hypothesize that pharmaceutical-embodied technical progress increases per capita output via its effect on labor supply (the employment rate and hours worked per employed person). We examine the effect of changes in both the average quantity and average vintage (FDA approval year) of drugs consumed on labor supply, using longitudinal, condition-level data.

The estimates indicate that conditions for which there were above-average increases in utilization of prescriptions during 1996-1998 tended to have above-average reductions in the probability of missed work days. The estimated value to employers of the reduction in missed work days appears to exceed the employer's increase in drug cost.

The estimates are also consistent with the hypothesis that an increase in a condition's mean drug vintage reduces the probability that people with that condition will experience activity and work limitations, and reduces their average number of restricted-activity days. The estimates imply that activity limitations decline at the rate of about one percent per year of drug vintage, and that the rate of pharmaceutical-embodied technical progress with respect to activity limitations is about 18\% per year. Estimates of the cost of the increase in drug vintage necessary to achieve reductions in activity limitations indicate that increases in drug vintage tend to be very "cost-effective."

Frank R. Lichtenberg

Columbia University

Graduate School of Business

726 Uris Hall

3022 Broadway

New York, NY 10027

and NBER

frank.lichtenberg@columbia.edu

phone: (212) 8544408

fax: (212) 3169355 
Per capita output is the most frequently used indicator of economic prosperity. Per capita output may be viewed as the product of three variables--output per hour worked, hours worked per employed person, and the employment rate:

$$
(\mathrm{Y} / \mathrm{P})=(\mathrm{Y} / \mathrm{H}) *(\mathrm{H} / \mathrm{E}) *(\mathrm{E} / \mathrm{P})
$$

where:

$$
\begin{aligned}
& \mathrm{Y}=\text { output } \\
& \mathrm{P}=\text { population } \\
& \mathrm{H}=\text { hours worked } \\
& \mathrm{E}=\text { employment }
\end{aligned}
$$

Hence factors that increase any of the three variables on the right-hand-side of eq. (1) will increase per capita output (Figure 1). ${ }^{1}$

In his seminal 1956 paper, Robert Solow showed that technical progress is necessary for there to be sustained growth in output per hour worked (Figure 2). In that paper, Solow assumed that technical progress was exogenous: it descends upon the economy like "manna from heaven," automatically and regardless of whatever else is going on in the economy (Jones (1998, 32-3)). More recent theoretical ("endogenous growth") models (Romer (1990)) relaxed this assumption: they have hypothesized that "technical progress is driven by research and development" ((Jones $(1998,89-90))$. Empirical evidence (e.g. Griliches and Lichtenberg (1984), Lichtenberg and Siegel (1991)) is consistent with the hypothesis that firms and industries that perform more R\&D exhibit higher productivity growth.

Solow and other economists have recognized since the late 1950s that there are two kinds of technical progress: disembodied and embodied. Suppose that agent $\mathrm{i}$ in the economy (e.g. a firm or government agency) engages in research and development. If technical progress is disembodied, another agent $(j)$ can benefit from agent i's $R \& D$ whether or not he purchases agent i's products. But if technical progress is embodied, agent $j$ benefits from agent i's $R \& D$ only if he purchases agent i's products. Solow

\footnotetext{
${ }^{1}$ Although they will increase per capita output, increases in the variables on the right-hand-side of eq. (1) will not necessarily increase social welfare. If people prefer being out of the labor force to working, an increase in the employment rate will reduce social welfare. If, on the other hand, people are prevented from working by illness and disability, then innovations that increase employment by enabling people to work will be welfare-enhancing. Such innovations are the focus of this paper.
} 
conjectured that most technical progress was embodied. In one paper (Solow (1962, p. 76)), he assumed that "all technological progress needs to be 'embodied' in newly produced capital goods before there can be any effect on output."

A number of econometric studies have investigated the hypothesis that capital equipment employed by U.S. manufacturing firms embodies technological change, i.e. that "each successive vintage of investment is more productive than the last." Equipment is expected to embody significant technical progress due to the relatively high R\&Dintensity of equipment manufacturers. According to the National Science Foundation, the R\&D-intensity of machinery and equipment manufacturing is about $50 \%$ higher than the R\&D-intensity of manufacturing in general, and 78\% higher than the R\&D intensity of all industries.

These studies have concluded that technical progress embodied in equipment is a major source of manufacturing productivity (output per hour) growth. Hulten (1992) found that as much as 20 percent (and perhaps more) of the BLS total-factor-productivity change (in manufacturing) can be directly associated with embodiment - the higher productivity of new capital than old capital. For equipment used in U.S. manufacturing, best-practice technology may be as much as 23 percent above the average level of technical efficiency. Bahk and Gort (1993) concluded that "Industrywide learning appears to be uniquely related to embodied technical change of physical capital. Once due account is taken of the latter variable, residual industrywide learning [disembodied technical change] disappears as a significant explanatory variable" (p. 579). And Sakellaris and Wilson (2000) estimate that "each vintage is about 12 percent more productive than the previous year's vintage (in the preferred specification)", and that equipment-embodied technical change accounted for about two thirds of U.S. manufacturing productivity growth between 1972 and 1996.

In this paper we test the hypothesis that another kind of embodied technical progress-pharmaceutical-embodied technical progress-has increased per capita output via its effect on labor supply (the employment rate and hours worked per employed person; see Figure 3) ${ }^{2,3,4}$ The pharmaceutical industry is even more R\&D-intensive than

\footnotetext{
${ }^{2}$ Rizzo et al (1996) examined the effect of prescribed medicine use on work-loss disability days of currently employed workers only; they did not consider the effect on the probability of being employed.
} 
the equipment industry: according to the NSF, the R\&D intensity of drugs and medicines manufacturing is $74 \%$ higher than the R\&D intensity of machinery and equipment manufacturing (Figure 4). Therefore, it is quite plausible that there is a high rate of pharmaceutical-embodied technical progress.

Data collected in the 1996 National Health Interview Survey indicate that $7 \%$ of people between the ages of 18 and 69 are completely unable to work due to illness and disability; another 5\% are limited in the kind and amount of the work they can do. Limitations in ability to work place individuals and families at major financial risk: people who are unable to work are more than three times as likely to live below the poverty threshold as people who are not limited, controlling for age, education, race, and sex. As Figure 5 shows, inability to work increases steadily with age: the rate is almost twice as high among 55-64 year-olds (15.2\%) as it is among 45-54 year-olds (7.9\%). ${ }^{5}$ This decline in ability to work with respect to age might be interpreted as age-related human capital depreciation. We hypothesize that use of newer drugs increases ability to work (or reduces the rate of human capital depreciation).

At first blush, one might think that employers need only be concerned about work- loss days experienced by currently employed persons. However firms make significant investments in recruitment and training of employees, and if these employees become unable to work, firms are unable to realize returns on these investments. Firms as well as workers incur human capital losses.

We will examine the effect of changes in drug utilization on labor supply using longitudinal, condition-level data on many major conditions in two different ways ${ }^{6}$. The first approach examines the effect of changes in the average quantity of drugs (and other

\footnotetext{
${ }^{3}$ Increased labor supply is not the only, or even the most important, benefit of new drugs. In previous papers (Lichtenberg $(1996,2001,2002)$ ), I have presented evidence that new drugs increase longevity and reduce expenditures on hospital care and other medical inputs.

${ }^{4}$ Data limitations prevent us from examining the effect of changes in drug utilization on output per hour worked. Berndt et al (1997) examined this effect in a study of pharmaceutical treatment for depression, anxiety, migraine, and hypertension among individuals employed by insurance claims processors. They found that pharmaceutical treatment increased both the number of hours worked and output (number of claims processed) per hour worked.

${ }^{5}$ Since older employed workers tend to earn more than younger employed workers, the percentage reduction in income from inability to work is even greater than the percentage reduction in employment.

${ }^{6}$ Case studies of the labor-supply effect of specific drugs or drugs for specific conditions have been performed. For example, Legg et al (1997) examined the effect of sumatriptan for treatment of migraine disease on employee productivity. They found that the value of the productivity increase was almost ten times as great as the incremental cost of the drug.
} 
medical services) consumed for a given condition, using data from the 1996-1998 waves of the Medical Expenditure Panel Survey (MEPS). The second approach examines the effect of changes in the average vintage (FDA approval year) of drugs consumed for a given condition; we hypothesize that drug quality tends to increase with vintage. This approach is based primarily on data from National Ambulatory Medical Care Surveys and National Health Interview Surveys during the period 1985-1996. Changes in quantity are positively correlated across conditions with changes in mean vintage, or quality: there is a significant positive correlation between the percentage increase between 1996 and 1998 in the total number of prescriptions for a condition and the fraction of 1996-1998 prescriptions that were for drugs approved after $1990 .^{7}$

\section{Why analysis at the aggregate (condition) level?}

We seek unbiased, efficient estimates of the parameters of the "health production function"- the effect of drug utilization on labor supply. The ideal way in which to obtain such estimates would be to randomly assign drugs to individuals, and observe their outcomes (labor supply), as in a randomized clinical trial (RCT). This is often infeasible, however. I will consider the problems that may arise in estimating health production functions in a non-experimental setting, and propose a simple and feasible solution to these problems.

I begin by postulating the following simple health production function:

$$
\mathrm{O}=\beta \mathrm{T}+\gamma \mathrm{P}
$$

where

$$
\begin{aligned}
& \mathrm{O}=\text { outcomes (post-treatment health status) } \\
& \mathrm{T}=\text { quantity of treatment (medical services consumed) } \\
& \mathrm{P}=\text { pre-treatment health status }
\end{aligned}
$$

For simplicity, we represent treatment intensity by a scalar (T), although in reality treatment involves a vector of inputs. I postulate that both $\beta$ and $\gamma$ are positive: post-

\footnotetext{
${ }^{7}$ Based on a sample of 74 2-digit ICD9 conditions, the correlation coefficient is 0.262 ( $\mathrm{p}$-value $\left.=0.024\right)$. Observations are weighted by the square root of the number of 1996-1998 prescriptions.
} 
treatment health status is positively related to both pre-treatment status and quantity of treatment.

My objective is to estimate $\beta$, the effect of treatment on outcomes, conditional on pre-treatment health status. The problem is that $P$ is often unobservable. If T were uncorrelated with $\mathrm{P}$ (which would be the case if treatment were randomly assigned to individuals, as in an RCT), the simple regression of $\mathrm{O}$ on $\mathrm{T}$ (i.e., without controlling for P) would still yield an unbiased estimate of $\beta$.

But this is not usually the case. In general, people with worse initial health (lower P) choose higher T. For example, older people tend to use more medical services and to have worse (pre-treatment) health than younger people.

Suppose that $\mathrm{T}=\pi \mathrm{P}$, and that $\pi<0$. This implies that

$$
\mathrm{P}=\pi^{-1} \mathrm{~T}
$$

Substituting (3) into (2),

$$
\mathrm{O}=\left(\beta+\gamma \pi^{-1}\right) \mathrm{T}
$$

The treatment coefficient in the simple outcomes regression (i.e. the effect of treatment on outcomes not conditioning on pre-treatment health) is a function of all three effects. Since $\pi^{-1}<0$, this coefficient is smaller than $\beta$, the effect of treatment on outcomes, conditional on pre-treatment health. Indeed, it is quite possible for $\left(\beta+\gamma \pi^{-1}\right)$ to be negative even though $\beta$ is positive: although treatment leads to improved outcomes, given $\mathrm{P}$, the simple correlation between treatment intensity and outcomes is negative. ${ }^{8}$

\footnotetext{
${ }^{8}$ Omitted-variables bias in production function estimation in other, non-health, areas (e.g., manufacturing) has long been recognized, although the bias there is often thought to operate in the opposite direction, i.e. overestimation of the marginal productivity of inputs. Chamberlin (1986) discusses the following classic example: 
When pre-treatment health status is not observable, estimates of the effect of treatment intensity on outcomes based on individual data are likely to be severely negatively biased. However this bias may be greatly reduced and perhaps even eliminated by aggregation. ${ }^{9}$ To see this, consider the following health production function:

$$
\mathrm{O}_{\mathrm{ijt}}=\beta \mathrm{T}_{\mathrm{ijt}}+\gamma \mathrm{P}_{\mathrm{ijt}}
$$

where the subscripts denote person $\mathrm{i}$ in group $\mathrm{j}$ in year $\mathrm{t}$. (Groups may be defined by disease, for example.) Aggregating (i.e., computing averages) across individuals, within groups and years,

$$
O_{\cdot j \mathrm{jt}}=\beta \mathrm{T}_{\cdot \mathrm{jt}}+\gamma \mathrm{P}_{\cdot \mathrm{jt}}
$$

where $\mathrm{O}_{\cdot \mathrm{jt}}=$ denotes the mean outcome of people in group $\mathrm{j}$ in year $\mathrm{t}$, etc. Suppose that mean pre-treatment health can be decomposed as follows:

$$
P_{\cdot j t}=\theta_{j}{ }^{\prime}+\delta_{t}{ }^{\prime}
$$

This allows there to be differences between groups in mean pre-treatment health in a given year, and for changes over time in the mean pre-treatment health of all groups. Substituting (5) into (4),

$$
\begin{aligned}
\mathrm{O}_{\cdot j \mathrm{jt}} & =\beta \mathrm{T}_{\cdot \mathrm{jt}}+\gamma \theta_{\mathrm{j}}{ }^{\prime}+\gamma \delta_{\mathrm{t}}{ }^{\prime} \\
& =\beta \mathrm{T}_{\cdot \mathrm{jt}}+\theta_{\mathrm{j}}+\delta_{\mathrm{t}}
\end{aligned}
$$

A is unobservable. In equilibrium, firms with higher A will have more employees, that is, the correlation between $\mathrm{A}$ and $\mathrm{N}$ is positive. As a result, the coefficient from the simple regression of $\mathrm{Y}$ on $\mathrm{N}$ is an overestimate of $\alpha_{1}$.

${ }^{9}$ Although analysis at the individual level is often preferable to analysis of aggregate data, aggregation is desirable under certain circumstances. See Grunfeld and Griliches (1960). 
where $\theta_{\mathrm{j}}=\gamma \theta_{\mathrm{j}}{ }^{\prime}$ and $\delta_{\mathrm{t}}=\gamma \delta_{\mathrm{t}}$ '. We can obtain consistent estimates of $\beta$ (the effect of treatment on outcomes) by estimating a model based on group-level panel data, with fixed group and year effects. In this context, variation in the relative treatment intensity of different groups $\left(\mathrm{T}_{\mathrm{.jt}}\right)$ is primarily due to exogenous medical innovations, rather than variation in pre-treatment health status.

\section{The effect of changes in the average quantity of drugs}

The 1996-1998 MEPS condition files report condition-specific data for each medical condition reported by each person in each year. It includes the following variables:

MISSWORK $_{\mathrm{ijt}}=1$ if one or more missed workdays were associated with condition $\mathrm{j}$ borne by person $\mathrm{i}$ in year $\mathrm{t}$

$=0$ otherwise

$\mathrm{RXNUM}_{\mathrm{ijt}}=$ the number of prescribed medicine events (prescriptions) associated with condition $\mathrm{j}$ borne by person $\mathrm{i}$ in year $\mathrm{t}$

OBNUM $_{\mathrm{ijt}}=$ the number of office-based events associated with condition $\mathrm{j}$ borne by person $\mathrm{i}$ in year $\mathrm{t}$

HSNUM $_{\mathrm{ijt}}=$ the number of hospital stays associated with condition $\mathrm{j}$ borne by person $\mathrm{i}$ in year $\mathrm{t}$

Aggregation of these data up to the condition-year level enables estimation of the following model ${ }^{10}$ :

MISSWORK $_{\cdot j t}=\beta_{\mathrm{RX}} \log \left(\mathrm{RXNUM}_{\cdot \mathrm{jt}}\right)+\beta_{\mathrm{OB}} \log \left(\mathrm{OBNUM}_{\cdot \mathrm{jt}}\right)$

$$
+\beta_{\mathrm{HS}} \mathrm{HSNUM}_{\cdot \mathrm{jt}}+\alpha_{\mathrm{j}}+\delta_{\mathrm{t}}+\varepsilon_{\mathrm{jt}}
$$

where

MISSWORK $_{. j t}=$ the fraction of people with condition $\mathrm{j}$ in year $\mathrm{t}$ who had one or more missed workdays associated with the condition

RXNUM $_{\text {jt }}=$ the average number of prescribed medicines associated with condition $\mathrm{j}$ in year $\mathrm{t}$

OBNUM.jt $_{\cdot}=$ the average number of office-based events associated with condition $\mathrm{j}$

\footnotetext{
${ }^{10}$ The hypothesis of diminishing marginal productivity of medical services implies that a logarithmic specification is appropriate. Since HSNUM .jt $_{\text {is }}$ frequently zero, we do not take the logarithm of this variable.
} 
borne by person $\mathrm{i}$ in year $\mathrm{t}$

HSNUM $_{\mathrm{jt}}=$ the average number of hospital stays associated with condition $\mathrm{j}$ in year $\mathrm{t}$

Including fixed condition effects $\left(\alpha_{j}\right.$ 's) and year effects $\left(\delta_{t}\right.$ 's) controls for the effect of any determinants of MISSWORK that vary across conditions but not over time and that vary over time but not across conditions. ${ }^{11}$ Estimation of this model will reveal whether conditions for which there were above-average increases in utilization of medical services (prescriptions, doctor visits, or hospital stays) tended to have above-average reductions in the fraction of people who had one or more missed workdays associated with the condition.

We restricted the sample to conditions borne by people between the ages of 18 and 65. The micro-level dataset contained 143,536 observations. The aggregated dataset contained about 280 observations (3 years times 93 2-digit ICD9 conditions/year).

Sample mean values of the variables are shown in the following table.

\begin{tabular}{|c|c|c|c|c|}
\hline year & misswork & rxnum & obnum & hsnum \\
\hline 1996 & 0.24 & 0.99 & 1.39 & 0.024 \\
\hline 1997 & 0.20 & 1.02 & 1.61 & 0.034 \\
\hline 1998 & 0.21 & 1.08 & 1.72 & 0.032 \\
\hline
\end{tabular}

With the exception of rxnum, the 1997 figures are much closer to the 1998 figures than they are to the 1996 figures. This may be related to the fact that 1996 was the first year of the survey, so that data for this year may be subject to greater measurement or reporting error than data for the subsequent two years. ${ }^{12}$

The probability that a condition was associated with one or more missed workdays ranged between $20 \%$ and $24 \%$. The average number of prescriptions per condition increased by 9\% from 1996 to 1998.

We estimated eq. (6) in two ways: probit estimation on grouped data, and weighted least-squares (WLS), weighting by the number of observations in each condition-year cell. Since the dependent variable of eq. (6) is bounded between zero and

\footnotetext{
${ }^{11}$ For example, suppose that both the probability of missing work days and the average number of prescriptions vary across regions, and that certain conditions tend to be more prevalent in certain regions. As long as the regional distribution of conditions remains stable over the sample period, fixed-effects estimation controls for the influence of region.

12 Since eq. (6) includes fixed year effects, changes in survey reporting and administration whose effects did not vary across conditions will not affect our results.
} 
one, probit estimation is theoretically superior. In practice, the two procedures yielded very similar results.

Weighted least-squares estimates of the key parameters of eq. (6) are shown in the following table:

\begin{tabular}{|l|r|r|r|}
\hline Parameter & \multicolumn{1}{|c|}{$\boldsymbol{\beta}_{\mathbf{R X}}$} & \multicolumn{1}{c|}{$\boldsymbol{\beta}_{\mathbf{O B}}$} & \multicolumn{1}{c|}{$\boldsymbol{\beta}_{\mathbf{H S}}$} \\
\hline estimate & -0.0414 & -0.0049 & 0.0208 \\
\hline std. error & 0.0155 & 0.0102 & 0.0623 \\
\hline t-statistic & -2.67 & -0.48 & 0.33 \\
\hline p-value & 0.0081 & 0.6323 & 0.7384 \\
\hline
\end{tabular}

The estimate of $\beta_{\mathrm{RX}}$ is negative and significantly different from zero, while the estimates of the other two parameters are far from statistically significant. When $\log ($ obnum) and hsnum are dropped from the equation, the estimate ( $\mathrm{p}$-value) of $\beta_{\mathrm{RX}}$ is $-.0498(0.0033)$. These estimates are consistent with the hypothesis that conditions for which there were above-average increases in utilization of prescriptions tended to have above-average reductions in the fraction of people who had one or more missed workdays associated with the condition.

An increase in the average number of prescriptions consumed for a condition is associated with a reduction in the probability of missing work days due to the condition. Suppose the average number of prescriptions increased by 1 per condition per year. We wish to compare the resulting increase in drug cost to the value of the estimated reduction in missed work days. To a first approximation, the increase in drug cost would simply be the average cost of a prescription, which was \$34.76 in 1996.

We will use the following formula to estimate the value of the reduction in missed work days from a unit increase in the number of prescriptions per condition per year:

$$
\begin{aligned}
\mathrm{V} & =(\mathrm{C} / \mathrm{H}) *(\mathrm{H} / \mathrm{D}) * \mathrm{E}(\mathrm{M} \mid \mathrm{M}>0) * \frac{\mathrm{d} \operatorname{prob}(\mathrm{M}>0)}{\mathrm{d} \text { RXNUM }} \\
& =(\mathrm{C} / \mathrm{H}) *(\mathrm{H} / \mathrm{D}) * \mathrm{E}(\mathrm{M} \mid \mathrm{M}>0) * \mathrm{RXNUM} *-\frac{\mathrm{d} \operatorname{prob}(\mathrm{M}>0)}{\mathrm{d} \log (\mathrm{RXNUM})} \\
& =(\mathrm{C} / \mathrm{H}) *(\mathrm{H} / \mathrm{D}) * \mathrm{E}(\mathrm{M} \mid \mathrm{M}>0) * \mathrm{RXNUM} *-\beta_{\mathrm{RX}}
\end{aligned}
$$

where 
$\mathrm{C}=$ employer costs for employee compensation

$\mathrm{H}=$ hours worked

$\mathrm{C} / \mathrm{H}=$ employer costs for employee compensation per hour worked

$\mathrm{D}$ = days worked

$\mathrm{H} / \mathrm{D}=$ hours worked per day

$\mathrm{M}=$ workdays missed

$\mathrm{E}(\mathrm{M} \mid \mathrm{M}>0)=$ expected number of workdays missed, given that some workdays were missed

$\underline{\operatorname{prob}(\mathrm{M}>0)}=$ probability that some workdays were missed

The sample mean value of RXNUM is 1.03, and our point estimate of $-\beta_{\mathrm{RX}}$ is .0498 .

According to the Bureau of Labor Statistics, in 1996 employer costs for employee

compensation per hour worked by civilian workers $(\mathrm{C} / \mathrm{H})$ was $\$ 18.68$. We assume that hours worked per day (H/D) is 7. The only remaining quantity we need to estimate in order to compute $\mathrm{V}$ is $\mathrm{E}(\mathrm{M} \mid \mathrm{M}>0){ }^{13}$

To estimate this, we combined person-level information from the 1996 MEPS Full- Year File with condition-level information from the 1996 MEPS Condition File. The first file provides information about the person's total number of missed work days associated with all medical conditions in $1996 .{ }^{14}$ The second file provides information about the number of medical conditions associated with any missed work days in 1996. The following table presents information about people classified by the latter characteristic:

\begin{tabular}{|l|r|r|r|}
\hline $\begin{array}{l}\text { Number of } \\
\text { conditions } \\
\text { associated with } \\
\text { missed work } \\
\text { days }\end{array}$ & $\begin{array}{l}\text { Number of } \\
\text { people }\end{array}$ & $\begin{array}{l}\text { Mean } \\
\text { number of } \\
\text { number of } \\
\text { missed } \\
\text { wissed } \\
\text { work days } \\
\text { per } \\
\text { condition }\end{array}$ \\
\hline 0 & 4120 & 0.18 & \\
\hline 1 & 3225 & 6.88 & 6.88 \\
\hline 2 & 1476 & 11.21 & 5.61 \\
\hline 3 & 660 & 15.62 & 5.21 \\
\hline 4 & 250 & 22.19 & 5.55 \\
\hline $5+$ & 175 & 28.36 & 4.59 \\
\hline
\end{tabular}

\footnotetext{
${ }^{13}$ Unfortunately the MEPS Condition Files indicate only whether any workdays were missed, not the number of workdays missed.

${ }^{14}$ This is the sum of missed workdays in rounds 1, 2, and 3 of the survey (ddnowrk1-ddnowrk3).
} 
There is a strong positive relationship between the number of conditions associated with missed work days and the mean number of missed work days. For example, people with one condition missed 6.70 more work days than people with zero conditions associated with missed work days. We will assume that $E(M \mid M>0)$ is a weighted average of the figures in the last column (weighted by the number of people), minus 0.18 (the mean number of missed work days of people with zero missed work-day conditions). Hence $\mathrm{E}(\mathrm{M} \mid \mathrm{M}>0)=6.24-0.18=6.06$. The average number of work-days missed per condition per year by people who missed any work days from a condition is 6.06.

Substituting these figures into eq. (7) yields an estimate of the value of the reduction in missed work days from a unit increase in the number of prescriptions per condition per year:

$$
\begin{aligned}
& \mathrm{V}=(\mathrm{C} / \mathrm{H}) *(\mathrm{H} / \mathrm{D}) * \mathrm{E}(\mathrm{M} \mid \mathrm{M}>0) * \mathrm{RXNUM} *-\beta_{\mathrm{RX}} \\
& =\$ 18.68 * 7 * 6.06 * 0498 \\
& =\$ 40.64 \text {. }
\end{aligned}
$$

A unit increase in the number of prescriptions per condition per year (a .97 increase in $\log (\mathrm{RXNUM})$ ) would reduce the probability of missing any work days by $5.1 \%$. Since $\mathrm{E}(\mathrm{M} \mid \mathrm{M}>0)=6.06$, it would reduce the expected number of missed work days by 0.31 days, or 2.18 hours. In 1996, the value to employers of this reduction in missed work days would have been $\$ 40.64$. This exceeds the average cost of a prescription in 1996 which was $\$ 34.76$. Moreover, employers did not bear the entire cost of the prescription. According to the 1997 MEDSTAT Marketscan database, which represents the inpatient and outpatient healthcare service use of individuals nationwide who are covered by the benefit plans of large employers, health plans, and government and public organizations, individuals paid 15 percent of the cost of their drug claims in the form of copayments. Hence the average cost to the employer of an additional prescription may have been $85 \% * \$ 34.76=\$ 29.66$. The estimated value to employers of the reduction in missed work days appears to exceed the employer's increase in drug cost. 


\section{The effect of changes in the average vintage of drugs}

In section A we will develop an econometric specification for testing the hypothesis that, ceteris paribus, the ability of a person with given medical conditions to work is positively related to the vintage(s) of the $\operatorname{drug}(\mathrm{s})$ he consumes for those conditions. ${ }^{15}$ In section $\mathrm{B}$, we describe the data used to estimate the model. Empirical results are presented in section $\mathrm{C}$.

\section{A. Econometric specification}

Consider the following model:

$$
\mathrm{L}_{\mathrm{ijt}}=\beta \mathrm{V}_{\mathrm{ijt}}+\alpha_{\mathrm{j}}+\delta_{\mathrm{t}}+\gamma \mathrm{Z}_{\mathrm{ijt}}+\varepsilon_{\mathrm{ijt}}
$$

where

$\mathrm{L}_{\mathrm{ijt}}=$ an indicator of the limitations imposed on person $\mathrm{i}$ by condition $\mathrm{j}$ in year $\mathrm{t}$ (80 conditions, $\mathrm{t}=1985,1989,1990, \ldots, 1996$ )

$\mathrm{V}_{\mathrm{ijt}}=$ an indicator (e.g. the mean) of the vintage of the drugs consumed by person $\mathrm{i}$ for condition $\mathrm{j}$ in year $\mathrm{t}$

$\mathrm{Z}_{\mathrm{ijt}}=$ other attributes (e.g. age) of person $\mathrm{i}$ with condition $\mathrm{j}$ in year $\mathrm{t}$

$\varepsilon_{\mathrm{ijt}}=$ a disturbance.

This model includes both condition fixed effects $\left(\alpha_{j}\right)$ and year fixed effects $\left(\delta_{t}\right)$.

Condition fixed effects control for the possibility that some conditions are inherently more limiting than others (independent of drug vintage). Some conditions tend to limit activities much more than others in a given year. For example, only $0.5 \%$ of the people who had chronic sinusitis (the second-most prevalent condition in 1990-1992) were limited by it in their major or outside activity, whereas $21.2 \%$ of the people who had arthritis (the third-most prevalent condition) were limited by it. Year fixed effects control for the influence of disembodied technical change and for other factors that change over time but do not vary across conditions.

\footnotetext{
${ }^{15}$ We define the vintage of a drug as the year in which the drug's active ingredient was first approved by the FDA.
} 
While eq. (8) is a useful starting point, for a number of reasons estimation of this model is neither feasible (due to missing data) nor necessarily appropriate (due to possible nonlinearity and interaction effects). We elaborate on these issues below.

Censoring of vintage data. The vintage data are censored from below: for drugs that have not been approved by the FDA since it was established in 1939, we know only that they are of pre-1939 vintage. One way of addressing the censoring problem is to replace $\mathrm{V}$ by a dummy variable (D) defined as follows:

$$
\begin{aligned}
\mathrm{D} & =1 \text { if } \mathrm{V}>\mathrm{V}^{*} \\
& =0 \text { if } \mathrm{V} \leq \mathrm{V}^{*},
\end{aligned}
$$

where $\mathrm{V}^{*}$ is a vintage threshold $\left(\mathrm{V}^{*} \geq 1939\right)$. Also define the following:

$$
\begin{aligned}
& \mathrm{V}_{\mathrm{N}}=\mathrm{E}\left(\mathrm{V} \mid \mathrm{V}>\mathrm{V}^{*}\right)=\text { mean vintage of "new drugs" } \\
& \mathrm{V}_{\mathrm{O}}=\mathrm{E}\left(\mathrm{V} \mid \mathrm{V} \leq \mathrm{V}^{*}\right)=\text { mean vintage of "old drugs" }
\end{aligned}
$$

Due to censoring, only the former is known. But this does not prevent us from testing the hypothesis that users of new drugs are less limited in activity than the users of old drugs, or from estimating the increase in drug cost required to achieve a given reduction in activity limitation.

Suppose we estimate the simple regression of L on D (for simplicity, here we ignore non-vintage determinants of $\mathrm{L}$ ). The slope of this regression is:

$$
\mathrm{b}_{\mathrm{LD}}=\mathrm{L}_{\mathrm{N}}-\mathrm{L}_{\mathrm{O}}
$$

where

$$
\begin{aligned}
& \mathrm{L}_{\mathrm{N}}=\mathrm{E}\left(\mathrm{L} \mid \mathrm{V}>\mathrm{V}^{*}\right)=\text { mean value of } \mathrm{L} \text { for "new drug" users } \\
& \mathrm{L}_{\mathrm{O}}=\mathrm{E}\left(\mathrm{L} \mid \mathrm{V} \leq \mathrm{V}^{*}\right)=\text { mean value of } \mathrm{L} \text { for "old drug" users }
\end{aligned}
$$

Hence, if the estimate of $b_{L D}$ is negative and significant, we may reject the null hypothesis that drug vintage has no effect on activity limitations.

One can also estimate the simple regression of drug price $(\mathrm{P})$ on $\mathrm{D}$. The slope of this regression is:

$$
b_{P D}=P_{N}-P_{O}
$$

where

$$
\mathrm{P}_{\mathrm{N}}=\mathrm{E}\left(\mathrm{P} \mid \mathrm{V}>\mathrm{V}^{*}\right)=\text { mean price of "new drugs" }
$$




$$
\mathrm{P}_{\mathrm{O}}=\mathrm{E}\left(\mathrm{P} \mid \mathrm{V} \leq \mathrm{V}^{*}\right)=\text { mean price of "old drugs" }
$$

Hence the ratio of $b_{P D}$ to - $b_{L D}$ is the ratio of the new-vs.-old drug price difference to the new-vs.-old drug reduction in activity limitations, i.e. the increase in drug cost required to achieve a given reduction in activity limitation.

$$
\frac{\underline{b}_{P D}}{-b_{L D}}=\frac{\underline{P}_{N}-P_{O}}{-\left(L_{N}-L_{O}\right)}
$$

In eq. (8), the parameter $\beta$ is the effect of a one-year increase in vintage on L. $\beta$ is related to $b_{\mathrm{LD}}$ as follows:

$$
\beta=\frac{\Delta \mathrm{L}}{\Delta \mathrm{V}}=\frac{\left(\underline{\mathrm{L}}_{\underline{N}}-\mathrm{L}_{\mathrm{O}}\right)}{\left(\mathrm{V}_{\mathrm{N}}-\mathrm{V}_{\mathrm{O}}\right)}=\frac{\mathrm{b}_{\mathrm{LD}}}{\left(\mathrm{V}_{\mathrm{N}}-\mathrm{V}_{\mathrm{O}}\right)}
$$

This implies that, to determine the effect of a one-year increase in vintage on $\mathrm{L}$, one needs to divide the dummy-variable regression coefficient by an estimate of $\left(\mathrm{V}_{\mathrm{N}}-\mathrm{V}_{\mathrm{O}}\right)$. Potential nonlinearity. If the relationship between $\mathrm{L}$ and $\mathrm{V}$ is linear, as hypothesized in eq. (8), then the choice of vintage threshold $\left(\mathrm{V}^{*}\right)$ won't affect the estimate of $\beta$ we obtain from eq. (9), e.g. it won't matter whether we define new drugs as post-1970 drugs or post-1980 drugs. However if the relationship is nonlinear-e.g., the reduction in activity limitations from switching from a 1980 to a 1990 drug is greater than the reduction in activity limitations from switching from a 1970 to a 1980 drug - then the choice of $\mathrm{V}^{*}$ will affect the estimate of $\beta$. This is illustrated by Figure 6 . Suppose that the vintage threshold is increased: $V^{*}$ shifts to the right. This will increase both $V_{N}$ and $V_{O}$, by different amounts (in general), and will also affect the slope of the straight line passing through the points $\left(\mathrm{V}_{\mathrm{O}}, \mathrm{L}_{\mathrm{O}}\right)$ and $\left(\mathrm{V}_{\mathrm{N}}, \mathrm{L}_{\mathrm{N}}\right)$. We will therefore estimate the model using several alternative vintage thresholds (1970, 1980, 1985, and 1990), both to check robustness and to investigate the possibility of nonlinearity.

Aggregation. We have data on $\mathrm{L}, \mathrm{V}$, and $\mathrm{Z}$, for large samples of individuals over a period of years. However the data on $\mathrm{L}$ and $\mathrm{V}$ come from different surveys and cover different individuals: data on condition-specific activity limitations come from the National Health Interview Survey—a household survey—and data on condition-specific drug utilization come from the National Ambulatory Medical Care Survey—a provider 
(physician) survey. Hence estimation of eq. (8) is not feasible. But by aggregating eq. (8) across individuals, we obtain an equation that can be estimated ${ }^{16}$ :

$$
L_{. j t}=\beta V_{. j t}+\alpha_{j}+\delta_{t}+\gamma Z_{. j t}+\varepsilon_{. j t}
$$

where

$L_{. j t}=$ is the mean value of $L_{i j t}$ for persons with condition $j$ in year $t$.

$\mathrm{V}_{\mathrm{j} \mathrm{jt}}=$ is the mean of the vintage indicator of drugs consumed for condition $\mathrm{j}$ in year $\mathrm{t}$.

For example, $\mathrm{L} \cdot \mathrm{jt}=$ is the fraction of people with arthritis in 1996 who are unable to work because of their arthritis, and $\mathrm{V}_{\text {.jt }}$ is the mean vintage of drugs prescribed to treat arthritis in 1996. If the estimate of $\beta$ from eq. (10) is negative and significant, that indicates that conditions with greater increases in vintage had greater declines (or smaller increases) in activity limitations.

Interaction effect. In eq. (10), the response of activity limitations to a change in vintage $(\beta=\partial \mathrm{L} / \partial \mathrm{V})$ is a constant. But it is reasonable to hypothesize that this response is proportional to the average number of drugs consumed by people with that condition:

$$
\beta=\beta^{\prime} N_{-} R_{j}
$$

where:

$\mathrm{N} \_\mathrm{Rx}_{\mathrm{j}}$ is the average annual number of prescriptions consumed for condition $\mathrm{j}$ by people with that condition.

Substituting eq. (11) into eq. (10),

$$
L_{. j t}=\beta^{\prime}\left(N_{-} R_{x} * V_{\cdot j t}\right)+\alpha_{j}+\delta_{t}+\gamma Z_{\cdot j t}+\varepsilon_{. j t}
$$

Due to censoring of vintage data discussed earlier, the best way to measure V given the available data is as the ratio of the number of new (e.g. post-1980) drugs prescribed for

\footnotetext{
${ }^{16}$ Estimation based on aggregate data may have advantages over estimation based on individual-level data. Suppose that the disturbance of eq. (8) is correlated with vintage, due to unobserved heterogeneity: people with more severe cases of a given condition may tend to take newer (or older) drugs for that condition. In this case, the estimate of $\beta$ from eq. (8) will be biased. But as long as the exogenous change in condition mean unobserved severity is uncorrelated with the change in mean vintage, the estimate of $\beta$ from eq. (10) will be unbiased.
} 
the condition to the total number of drugs prescribed for the condition. Since N_Rx is the ratio of the total number of drugs prescribed for the condition to the number of people with the condition, (N_Rx*V) equals the number of new drugs prescribed for the condition per person with the condition. For example, if $\left(\mathrm{N} \_\mathrm{Rx} * \mathrm{~V}\right)=1$ in 1996, that means that, on average, people with the condition are taking one new drug for that condition.

Now consider the costs and benefits of a unit increase in (N_Rx * V). A possible estimate of this cost is the average cost of a prescription for a new drug. NAMCS does not contain any information about drug costs, but according to the 1997 MEPS, the average cost of a prescription for a post-1980 drug in 1997 was $\$ 59.08$. If use of the new drug did not reduce use of old drugs, this would be a reasonable estimate of the cost of a unit increase in $\left(\mathrm{N} \_\mathrm{Rx} * \mathrm{~V}\right)$. However in reality, use of new drugs is likely to reduce use of old drugs (Lichtenberg and Philipson (2002)). If there were 1-for-1 substitution of new for old drugs, the cost of the unit increase in (N_Rx * V) would be the difference between the price of the new drug and the price of the old drug. The average cost of a prescription for a pre-1980 drug in 1997 was $\$ 26.66$, so this price difference is $\$ 32.42$.

The benefit, in dollar terms, of a unit increase in $\left(\mathrm{N} \_\mathrm{Rx} * \mathrm{~V}\right)$ is the reduction in the probability of experiencing the limitation (- $\beta$ ') times the value of, or willingness to pay for, freedom from the limitation (WTP). Suppose, for example, that consuming one new drug (increasing $\left(\mathrm{N} \_\mathrm{Rx} * \mathrm{~V}\right)$ by 1$)$ reduces the probability of being unable to work by .03 (from $8 \%$ to $5 \%$ ). If the value of being able to work is $\$ 35,000$ - about the average annual earnings of American workers - then the benefit of reducing this activity limitation is $\left(-\beta^{\prime}\right) * \mathrm{WTP}=.03 * \$ 35,000=\$ 1050$. If the benefit of the increase in drug vintage exceeds its cost, the increase in vintage raises social welfare.

\section{B. Data}

\section{Limitations of activity, by condition and year}

Numerous health surveys (e.g., the Medical Expenditure Panel Survey) collect data on respondents' activity limitations, including limitation in ability to work. But people with activity limitations often suffer from multiple conditions, and these surveys 
do not indicate which conditions are responsible for their activity limitations ${ }^{17}$. The National Health Interview Survey is the only survey we are aware of that collects condition-specific activity limitation data.

The purpose of the National Health Interview Survey (NHIS) is to obtain information about the amount and distribution of illness, its effects in terms of disability and chronic impairments, and the kinds of health services people receive.

Condition-Condition is a general term that includes any specific illness, injury, or impairment. Condition data are derived from the survey in two ways. First, respondents are asked to identify any conditions that caused certain types of impact associated with health, such as a visit to a doctor or a day spent in bed. Second, respondents are read lists of selected chronic conditions and asked whether they or any family members have any of these conditions. The latter information is used in making prevalence estimates. At a later point in the survey, a series of questions is asked about each of the conditions identified in either of the two ways just described. The information obtained on each condition helps to clarify the nature of the condition and whether medical services have been involved in its diagnosis or treatment. It also aids in the coding of the condition. All conditions except impairments are coded according to the ninth revision of the International Classification of Diseases (5) with certain modifications adopted to make the codes more suitable for information derived from a household survey.

Chronic condition-A condition is considered chronic if the respondent indicates it was first noticed more than 3 months before the reference date of the interview, or it is a type of condition that ordinarily has a duration of more than 3 months. Examples of conditions that are considered chronic regardless of their time of onset are diabetes, heart conditions, emphysema, and arthritis. ${ }^{18}$

\footnotetext{
171996 MEPS data indicate that among people with at least one medical condition, $79 \%$ had 2 or more conditions, $60 \%$ had 3 or more, and $31 \%$ had five or more. Moreover $95 \%$ of conditions are borne by people with 2 or more conditions, $60 \%$ of conditions are borne by people with 5 or more conditions, and $18 \%$ of conditions are borne by people with 10 or more conditions.

${ }^{18}$ The majority of conditions reported in the condition file are chronic conditions. For example, $86 \%$ of conditions reported in 1996 were chronic conditions.
} 
Limitation of activity because of chronic conditions- Persons are classified in terms of the major activity usually associated with their particular age group. The major activities for the age groups are:

1. Ordinary play for children under 5 years of age

2. Attending school for those $5-17$ years of age

3. Working or keeping house for persons 18-69 years of age

4. Capacity for independent living (for example, the ability to bathe, shop, dress, eat, and so forth, without needing the help of another person) for those 70 years of age and over

People 18-69 years of age who are classified as keeping house are also classified by their ability to work at a job or business. (In Collins (1997), the major activity of persons 6569 years is assumed to be working or keeping house; however, questions were also asked about the capacity for independent living in this age group, which would permit an alternative definition of limitation.)

In regard to these activities, each person is classified into one of four categories:

1. Unable to perform the major activity

2. Able to perform the major activity but limited in the kind or amount of this activity

3. Not limited in the major activity but limited in the kind or amount of other activities

4. Not limited in any way

In regard to these four categories, NHIS publications often classify persons only by whether they are limited (groups 1-3) or not limited (group 4). Persons are not classified as limited in activity unless one or more chronic conditions are reported as the cause of the activity limitation. If more than one condition is reported, the respondent is asked to identify the condition that is the major cause of the limitation.

Condition Record File - This file contains information for each reported health condition. NHIS condition records can be used to calculate aggregate estimates and rates of the incidence of acute conditions, prevalence of selected chronic conditions, disability days and utilization associated with acute or chronic conditions, and chronic conditions causing limitation of activity. The Condition file contains the following types of records:

1. Condition records, either acute or chronic, which are associated with disability days, doctor visits and/or hospitalizations in the two weeks preceding the interview. 
2. Chronic condition records when the condition is reported to be the main or secondary cause of activity limitation or limitation in ability to work.

3. Chronic condition records reported in response to a checklist of conditions for each body system, e.g., digestive. The total sample was divided into six sub-samples. Each sub-sample was asked the set of conditions corresponding to one of the six chronic disease checklists.

To calculate limitation of activity due to chronic conditions on a condition basis, NCHS (1996, p. 51) says that all chronic condition records, not just those reported in response to a checklist of conditions for each body system, should be used.

\section{Vintage distribution of drugs utilized, by condition and year}

National Ambulatory Medical Care Surveys offer information on patients' visits to a national sample of office-based physicians. The surveys collect information on all drugs/medications ordered, administered, or provided during office visits. The data items include medication code, generic name and code, brand name, entry status, prescription status, federal controlled substance status, composition status, and related ingredient codes. Also included are demographic items describing the patient, such as age, sex, race, and ethnicity. The universe consists of office visits to nonfederally employed physicians classified by the American Medical Association (AMA) or the American Osteopathic Association (AOA) as "office-based, patient care" (excluding specialties of anesthesiology, pathology, and radiology), from 112 Primary Sampling Units (PSUs) in the United States.

Each NAMCS office visit record reports the physician's diagnoses, any drugs prescribed (including the names of each of the ingredients of combination drugs), and a sampling weight. Hence one can calculate, for each year in which NAMCS was conducted, the joint distribution of prescribed medicines, by drug and diagnosis ${ }^{19}$.

To determine the vintages (FDA approval dates) of drugs reported in NAMCS, we used two unpublished files obtained from the FDA. The first is a list of all of the 821 new molecular entities (NMEs) approved during the period 1950-1993. The second is a

\footnotetext{
${ }^{19}$ Up to three diagnoses may be recorded; when multiple diagnoses are recorded, we allocate the drugs prescribed equally across the diagnoses.
} 
list of all new drug applications (NDAs) approved during the period 1939-1998. (The first FDA drug approval occurred in 1939.) This list includes both new molecular entities approved and other NDAs approved (new formulations, new manufacturers, etc.). Although the two lists are broadly consistent, there are some discrepancies. Figure 7 shows the number of new molecular entities approved per year, as computed from both lists. $^{20}$ We consider the first list to be more reliable for the 1950-1993 period, since the FDA constructed it for the specific purpose of identifying NMEs approved during the period. We use the second list only to provide data on NMEs approved during 19391949 and 1994-1998. We matched NAMCS generic drug names to ingredient names contained in FDA new molecular entity approvals.

Some drugs existed before the FDA was established in 1939. The vintages of these drugs are unknown — it is only known that they are of pre-1939 vintage. In 1980the first year in which NAMCS collected drug data--about $60 \%$ of prescriptions were for drugs of pre-1939 vintage. By 1998, this fraction had declined to about $40 \% .^{21}$

To obtain meaningful indicators of the vintage distribution of drugs by condition and year, we must address the problem posed by the censoring of this distribution. There are two ways to do this. One is to impute a (reasonable) vintage value for drugs of unknown (pre-1939) vintage. This allows estimation of the mean vintage of all prescriptions, including those of unknown vintage. Figure 8 shows the mean vintage of prescriptions, by year, when the value 1900 is imputed to drugs with missing vintages. When this imputation is used, the mean age (= year prescribed - vintage) of drugs is fairly stable, but declines slightly, from about 55 years during 1980-85 to about 52 years during 1989-98.

A second approach is to use indicators such as those shown in Figure 9, i.e. the fraction of drugs prescribed for condition $\mathrm{j}$ in year $\mathrm{t}$ of vintage greater than $\mathrm{v}_{0}$ (e.g. $\mathrm{v}_{0}=$ 1970, 1980, and 1990). The fraction of prescriptions that were for drugs approved after

\footnotetext{
${ }^{20}$ We also merged the two lists, by new drug approval number, and calculated the difference in approval years recorded in the two lists. The mean and median differences were both approximately zero, and $98 \%$ of the differences were between -2 and +2 years, but there were 5 cases in which the absolute difference exceeded 10 years.

${ }^{21}$ These figures treat a prescription for a combination drug — a drug with multiple ingredients — as a prescription for each ingredient. For example, a prescription for a drug containing the two ingredients benzalkonium chloride and tyloxapol is treated as two prescriptions, one for each ingredient.
} 
1970 increased from $7.8 \%$ in 1980 to $31.2 \%$ in 1990 , and to $40.3 \%$ in 1998 . We will try both of these approaches.

Table 1 lists the 50 most frequent generic substances in drug mentions at office visits in 1994-1996.

As Figure 10 shows, there is considerable variation across conditions with respect to the rate of change in the drug vintage distribution. The Figure shows the percent of 1998 prescriptions that were for drugs approved by the FDA after 1980, by condition, for conditions with more than 20 million prescriptions in 1998. About half of the drugs used for three major conditions-DISEASES OF OTHER ENDOCRINE GLANDS, HYPERTENSIVE DISEASE, and NEUROTIC DISORDERS, PERSONALITY DISORDERS, AND OTHER NONPSYCHOTIC MENTAL DISORDERS - were post1980 drugs. In contrast, only one-sixth of the drugs used for three other major conditions-ACUTE RESPIRATORY INFECTIONS, DISEASES OF THE EAR AND MASTOID PROCESS, and OTHER DISORDERS OF FEMALE GENITAL TRACTwere post-1980 drugs. We will rely on this (presumably exogenous) cross-condition variation in the change in the vintage distribution to identify the effect of vintage on activity limitations.

\section{Average annual number of prescriptions consumed, by condition}

The average annual number of prescriptions consumed, by condition $\left(\mathrm{N}_{-} \mathrm{Rx}_{\mathrm{j}}\right.$ in eq. (12)), can be calculated for two different years during our 1985-1996 sample period from the medical conditions files of two household surveys: the 1987 National Medical Expenditure Survey and the 1996 Medical Expenditure Panel Survey. Each of these files contains about 75,000 condition records. We calculated the mean number of prescriptions consumed, by (2-digit ICD9) condition, in each year; $\mathrm{N}_{-} \mathrm{Rx}_{\mathrm{j}}$ is the mean of the 1987 and 1996 condition-j means. ${ }^{22}$

\section{Prescription prices and vintages}

\footnotetext{
${ }^{22}$ The average number of prescriptions per condition was 1.22 in 1987 and 1.04 in 1996.
} 
Estimation of price differences between new and old drugs requires data on the prices and vintages of a cross-section of prescriptions. We obtained data on prescription prices from the 1997 MEPS Prescribed Medicines file, which contains price data for 234,473 prescriptions, coded by National Drug Code number. Using Multum's denorm table, we determined the names of the active ingredients contained in each of these prescriptions. To determine vintages of these prescriptions, we matched these ingredient names to the ingredient names contained in FDA new molecular entity approvals (described above).

\section{Empirical results}

We estimated eq. (12) for five different measures of the (dependent) activity limitation variable (L), and using five alternative definitions of the vintage variable (V). The activity limitation variables are:

main_act_limit $=$ number of people with condition whose major activity is limited, mainly due to this condition, as \% of total number of people with condition

main_work_limit $=$ number of people with condition whose ability to work is limited, mainly due to this condition, as \% of total number of people with condition

any_work_limit $=$ number of people with condition whose ability to work is limited, mainly or secondarily due to this condition, as $\%$ of total number of people with condition

unable_work = number of people with condition who are unable to work, mainly due to this condition, as $\%$ of total number of people with condition

restricted_days $=$ mean number of restricted activity days due to this condition in the two weeks preceding the interview

The five alternative definitions of the vintage variable $\operatorname{are}^{23}$ :

V_Mean = mean vintage of drugs consumed by people with the condition (setting the vintage of drugs of missing vintage to 1900)

\footnotetext{
${ }^{23}$ Each of these variables is multiplied by mean number of prescriptions consumed for the condition.
} 
POST70 = number of post-1970 drugs consumed by people with the condition as $\%$ of total number of drugs consumed by people with the condition

POST $80=$ number of post-1980 drugs consumed by people with the condition as $\%$ of total number of drugs consumed by people with the condition

POST85 = number of post-1985 drugs consumed by people with the condition as $\%$ of total number of drugs consumed by people with the condition

POST90 = number of post-1990 drugs consumed by people with the condition as $\%$ of total number of drugs consumed by people with the condition

The sample includes chronic conditions experienced by people between the ages of 18 and 69 in the years 1985 and 1989-1996. ${ }^{24}$ The micro-level data set contains about 320,000 observations. The data were aggregated by 2-digit ICD9 code and year; the aggregate data set contains about 630 observations ( 9 years * about 70 conditions). The model was estimated using weighted least squares (WLS), with the weight equal to the number of sample conditions in that condition-year cell. ${ }^{25}$ All models include the following covariates: condition fixed effects, year fixed effects, mean age, mean years of schooling, percent male, and percent white.

The estimates are presented in Table 2. Estimates in the first column are based on the first vintage measure, mean vintage of drugs consumed for the condition. The coefficients on this measure are negative and highly significant for four of the five dependent variables (all except unable_work). This is consistent with the hypothesis that an increase in a condition's mean drug vintage reduces the probability that people with that condition will experience activity and work limitations, and reduces their average number of restricted-activity days.

Estimates in the second column are based on the "new drug share", using the lowest vintage threshold (1970). Not surprisingly (due to potentially erroneous missing-value imputations in the first measure), this variable is more strongly (inversely) related to all

\footnotetext{
${ }^{24}$ The NHIS collected consistent data on chronic conditions from 1982 to 1996 (major changes were made to the survey in 1997), but NAMCS was not conducted in 1982-1984 and in 1986-1988. It has been conducted annually since 1989.

${ }^{25}$ Since most of the dependent variables are bounded between zero and one, we also computed probit estimates of some models. The results were very consistent with the WLS estimates: the probit t-statistics on the vintage coefficient were generally about $20 \%$ smaller than the WLS t-statistics, but probit p-values were also generally <.001. Since WLS coefficients are easier to interpret than probit coefficients, we report WLS estimates.
} 
of the activity limitation measures than mean vintage is: all of the t-statistics are higher in column 2 than they are in column 1. All of the dependent variables are negatively and significantly (at the .02 or lower level) related to POST70. ${ }^{26}$

The remaining three columns are also based on the "new drug share" measure of vintage, but use increasing vintage thresholds (1980, 1985, and 1990). With only one exception (the POST90 coefficient in the restricted_days regression), all of the vintage coefficients are negative and highly statistically significant. Thus, the finding of a significant negative effect of drug vintage on activity limitations appears to be quite robust to alternative vintage measures and definitions of activity limitations.

Now we will test the sensitivity of the estimates (based on the 1980 vintage threshold) to two other changes in model specification. The drug vintage measures used in the regressions reported in Table 2 were based on all NAMCS drug mentions. About $10 \%$ of NAMCS drug mentions are for nonprescription (over-the-counter (OTC)) drugs; about one sixth are for combination drugs. The first column of Table 3 shows estimates of the vintage coefficient when OTC and combination drugs are included; the second column shows estimates when they are excluded. Excluding OTC and combination drug mentions has very little effect on the estimated vintage coefficients.

The third column of Table 3 shows estimates of vintage coefficients when we include an additional covariate in the model: $\log \left(\mathrm{PREV}_{\mathrm{jt}}\right)$, where $P R E V_{\mathrm{jt}}$ is the estimated prevalence of (number of people reporting) condition $\mathrm{j}$ in year $\mathrm{t}$. In principle, it is possible that the introduction of new drugs for a condition could induce people with mild, previously-unreported cases of the condition, to begin reporting it. As a result, the average reported severity of the condition (e.g. inability to work) would decline, but this would be due to an increase in reporting. The data provide no support for this hypothesis, however: the coefficients on $\log \left(\mathrm{PREV}_{\mathrm{jt}}\right)$ are generally (weakly) positive, indicating that severity and reported prevalence tend to move in the same direction, not in opposite directions. Moreover, controlling for reported prevalence has very little effect on the estimated vintage coefficients. Given this apparent robustness, we base the remainder of our analysis on the estimates presented in Table 2.

\footnotetext{
${ }^{26}$ NHIS collects data on subcategories of restricted activity days, i.e. work-loss days and bed-days. Vintage coefficients were never significant in regressions of these more detailed measures.
} 
Recall that the vintage coefficients in columns 2 through 5 in Table 2 should be interpreted as new-drug vs. old-drug differences in mean limitations $\left(\mathrm{L}_{\mathrm{N}}-\mathrm{L}_{\mathrm{O}}\right)$, and that to determine the effect of a one-year increase in vintage on $\mathrm{L}$, one needs to divide these coefficients by an estimate of $\left(\mathrm{V}_{\mathrm{N}}-\mathrm{V}_{\mathrm{O}}\right)$. Vintages of pre-1939 drugs are unknown, but if we exclude pre-1939 drugs - and redefine old drugs as drugs for which (1939 $\leq$ vintage $\leq$ $\left.\mathrm{V}^{*}\right)$-we can calculate $\left(\mathrm{L}_{\mathrm{N}}-\mathrm{L}_{\mathrm{O}}\right) /\left(\mathrm{V}_{\mathrm{N}}-\mathrm{V}_{\mathrm{O}}\right) .{ }^{27}$ To determine the percentage effect on $\mathrm{L}$ of a one-year increase in vintage, we divide this ratio by the mean value of L. Estimated percentage reductions in activity limitations from a one-year increase in vintage (based on $\left.\mathrm{V}^{*}=1985\right)$ are:

\begin{tabular}{|l|r|}
\hline main_act_limit & $1.0 \%$ \\
\hline main_work_limit & $1.1 \%$ \\
\hline any_work_limit & $0.8 \%$ \\
\hline unable_work & $1.2 \%$ \\
\hline restricted_days & $1.0 \%$ \\
\hline
\end{tabular}

These estimates imply that activity limitations decline at the rate of about one percent per year of drug vintage. Previous authors have argued that the annual rate of embodied technical progress should be measured as the percentage change in output from a oneyear increase in the vintage of an input divided by the input's share in total cost of production. ${ }^{28}$ CMS data indicate that during the period 1985-1996, the average share of prescription drug expenditure in national health expenditure was $5.6 \%$. This implies that the rate of pharmaceutical-embodied technical progress with respect to activity limitations was about $18 \%$ per year. ${ }^{29}$

As discussed above, by combining these estimates with data on the average prices of new and old drugs, we can estimate the cost of the increase in drug vintage necessary to achieve reductions in activity limitations. If use of a new drug does not reduce use of

\footnotetext{
${ }^{27}$ We calculate this by including two vintage variables in the model, e.g. POST39-the number of post1939 drugs consumed by people with the condition as \% of total number of drugs consumed by people with the condition-and POST85, and dividing the POST85 coefficient by the difference between the mean vintage of 1939-1985 drugs (=1968) and the mean vintage of post-1985 drugs (=1989). (In these regressions, the POST39 coefficient is never statistically significant.)

${ }^{28}$ In other words, if an input improves at the rate of $20 \%$ per year, and the input accounts for $5 \%$ of total cost of production, than improvement in the input causes output to increase $1 \%(=5 \% * 20 \%)$ per year.

${ }^{29}$ As noted above, Sakellaris and Wilson (2000) estimate that "each vintage [of manufacturing equipment] is about 12 percent more productive than the previous year's vintage (in the preferred specification)."
} 
old drugs, the cost of a unit increase in $\left(\mathrm{N} \_\mathrm{Rx} * \mathrm{~V}\right)$ is $\mathrm{P}_{\mathrm{N}}$. If, on the other hand, there is 1-for-1 substitution of new for old drugs, the cost of the unit increase in (N_Rx * V) would be the difference between the price of the new drug and the price of the old drug $\left(\mathrm{P}_{\mathrm{N}}-\mathrm{P}_{\mathrm{O}}\right)$. For convenience, we refer to these as upper- and lower-bound estimates, respectively, of the cost of a unit increase in $\left(\mathrm{N} \_\mathrm{Rx} * \mathrm{~V}\right)$. To estimate cost per unit reduction in an activity limitations variable, we divide either $\mathrm{P}_{\mathrm{N}}$ or $\left(\mathrm{P}_{\mathrm{N}}-\mathrm{P}_{\mathrm{O}}\right)$ by minus the vintage coefficient.

These calculations are shown in Table 4. Because the dependent variable in the restricted_days regression was the mean number of restricted activity days due to this condition in just the two weeks preceding the interview, we "annualized" these coefficients by expressing them as percentages of average 2-week restricted activity days (i.e., we divided by $.838=$ mean(restricted_days)), and then multiplied by average annual restricted activity days per person due to chronic conditions (8.3 days). The annualized coefficients are about ten times as large in magnitude as the original (2-week) coefficients.

The last column of Table 4 shows the average (across the 4 vintage thresholds) estimate of the vintage cost of reduced activity limitations. The "upper bound" average estimate of the vintage cost of enabling a person to work (unable_work) is \$2570; the "lower bound" average estimate is just over half as much (\$1357). The average annual earnings of a full-time year-round American worker are currently in the neighborhood of $\$ 35,000$. Hence the increase in vintage would be "cost-effective," even if the earnings of the person enabled to work were a small fraction (e.g. 10\%) of average earnings. Costs of reducing work limitations and activity limitations in general are about half as great as the cost of shifting the person from completely unable to work to able to work.

The upper- and lower-bound estimates of the cost of achieving one less restrictedactivity day are $\$ 34$ and $\$ 18$, respectively. Average daily employee compensation is currently about $\$ 140$, about four times the upper-bound estimate. Though smaller than the other ratio of benefit to cost, the vintage-induced reduction in restricted activity days also appears to be highly "cost-effective."

Finally, notice that the vintage cost of reducing activity limitations generally declines as the vintage threshold $\left(\mathrm{V}^{*}\right)$ increases. While these differences may not be 
statistically significant, they suggest that the relationship between vintage and activity limitations may be nonlinear-e.g., that the reduction in activity limitations from switching from a 1980 to a 1990 drug was greater than the reduction in activity limitations from switching from a 1970 to a 1980 drug.

\section{Summary and Conclusions}

Per capita output depends on ability to work and labor supply as well as on output per hour worked. Previous research indicates that R\&D-driven technical progress (often embodied technical progress) has been the major source of increase in output per hour worked. Pharmaceuticals are about three times as R\&D-intensive as other goods and services. We hypothesized that pharmaceuticalembodied technical progress increases per capita output via its effect on labor supply (the employment rate and hours worked per employed person). If this is the case, the ability of a person with given medical conditions to work is positively related to the vintage of the drug(s) he consumes for those conditions, ceteris paribus. Since inability to work increases steadily with age, an alternative way of stating this hypothesis is that use of newer drugs reduces the rate of human capital depreciation.

First we examined the effect of changes during 1996-1998 in the average number of prescriptions consumed for a condition on the probability of missed work days. The estimates indicated that conditions for which there were above-average increases in utilization of prescriptions tended to have above-average reductions in the probability of missed work days. The estimated value to employers of the reduction in missed work days appears to exceed the employer's increase in drug cost.

We then examined, using different data, the effect of changes during 1985-1996 in the average vintage of prescriptions consumed for a condition on five different, condition-specific measures of activity limitation, including limits on ability to work. There was considerable variation across conditions with respect to the rate of change in the drug vintage distribution; we relied on this to identify the effect of vintage on activity limitations. 
The estimates were consistent with the hypothesis that an increase in a condition's mean drug vintage reduces the probability that people with that condition will experience activity and work limitations, and reduces their average number of restricted-activity days. The finding of a significant negative effect of drug vintage on activity limitations appeared to be quite robust to alternative vintage measures and definitions of activity limitations. The estimates implied that activity limitations decline at the rate of about one percent per year of drug vintage, and that the rate of pharmaceutical-embodied technical progress with respect to activity limitations is about $18 \%$.

By combining these estimates with data on the average prices of new and old drugs, we estimated the cost of the increase in drug vintage necessary to achieve reductions in activity limitations. We calculated both "upper-bound" estimates-which assume that use of a new drug does not reduce use of old drugs - and "lower-bound estimates"- which assume that there is 1 -for- 1 substitution of new for old drugs.

The "upper bound" average estimate of the vintage cost of enabling a person to work is \$2570; the "lower bound" average estimate is just over half as much (\$1357). Since the average annual earnings of a full-time year-round American worker is about $\$ 35,000$, the increase in vintage would be "cost-effective," even if the earnings of the person enabled to work were a small fraction (e.g. 10\%) of average earnings. Costs of reducing work limitations and activity limitations in general are about half as great as the cost of shifting the person from completely unable to work to able to work.

The upper- and lower-bound estimates of the cost of achieving one less restrictedactivity day are $\$ 34$ and $\$ 18$, respectively. Average daily employee compensation is currently about $\$ 140$, about four times the upper-bound estimate. Though smaller than the other ratio of benefit to cost, the vintage-induced reduction in restricted activity days also appears to be highly "cost-effective."

The evidence suggests that the relationship between vintage and activity limitations may be nonlinear-e.g., that the reduction in activity limitations from switching from a 1980 to a 1990 drug was greater than the reduction in activity limitations from switching from a 1970 to a 1980 drug. 


\section{References}

Bahk, Byong-Hyong and Michael Gort (1993), "Decomposing Learning by Doing in New Plants”, Journal of Political Economy, 101, 561-583.

Berndt, Ernst, Stan N. Finkelstein, Paul E. Greenberg, Alison Keith, and Howard Bailit (1997), "Illness and Productivity: Objective Workplace Evidence," MIT Sloan School of Management Program on the Pharmaceutical Industry, Working paper no. 42-97, May.

Chamberlin, Gary (1986), "Panel Data", Chapter 22 of Handbook of Econometrics, vol. 2, ed. by Zvi Griliches and Michael Intriligator (North Holland).

Collins, J. G. (1997), Prevalence of selected chronic conditions: United States, 19901992. National Center for Health Statistics. Vital Health Stat 10(194).

Griliches, Zvi, and Frank Lichtenberg (1984), "R\&D and Productivity at the Industry Level: Is There Still a Relationship?," in $R \& D$, Patents, and Productivity, Zvi Griliches, ed. (Chicago: Univ. of Chicago Press).

Grunfeld, Yehuda and Griliches, Zvi (1960), "Is Aggregation Necessarily Bad?" Review of Economics and Statistics, February, pp. 1-13.

Hulten, Charles R. (1992), "Growth Accounting When Technical Change is Embodied in Capital,” The American Economic Review, Vol. 82, No. 4. (Sept.), pp. 964-980.

Jones, Charles I. (1998), Introduction to Economic Growth (New York: Norton).

Legg RF, Sclar DA, Nemec NL, Tarnai J, Mackowiak JI. (1997), "Cost benefit of sumatriptan to an employer," J Occup Environ Med 39(7):652-7.

Lichtenberg, Frank (1996), "Do (More and Better) Drugs Keep People Out of Hospitals?," American Economic Review 86, May, 384-8.

(2001), "Are the Benefits of Newer Drugs Worth Their Cost?

Evidence from the 1996 MEPS," Health Affairs 20(5), September/October 2001, 241-51.

(2002), "Pharmaceutical Innovation, Mortality Reduction, and

Economic Growth," in The Value of Medical Research, ed. by Kevin Murphy and Robert Topel (University of Chicago Press, forthcoming).

(2002), "Pharmaceutical Knowledge-Capital Accumulation and

Longevity," in Measuring Capital in the New Economy, ed. by Carol Corrado, John Haltiwanger, and Dan Sichel, (University of Chicago Press, forthcoming). 
Lichtenberg, Frank, and Tomas Philipson (2001), “The Dual Effects of Intellectual Property Regulations: Within- and Between-Patent Competition in The US Pharmaceuticals Industry," working paper, December.

Lichtenberg, Frank, and Donald Siegel (1991), "The Impact of R\&D Investment on Productivity: New Evidence Using Linked R\&D-LRD Data," with Donald Siegel, Economic Inquiry 29 (April), 203-28.

Nelson C, Woodwell D. (1998), National Ambulatory Medical Care Survey: 1993 Summary. National Center for Health Statistics. Vital Health Stat 13(136).

National Center for Health Statistics (1999), National Health Interview Survey, 1996: Codebook and Questionnaires, First ICPSR Version, April 1999, Inter-university Consortium for Political and Social Research, Ann Arbor, Michigan.

Rizzo, J., T. Abbott, and S. Pashko, "Labour Productivity Effects of Prescribed Medicines for Chronically Ill Workers," Health Economics, vol. 5: 249-265 (1996).

Sakellaris, Plutarchos and Dan Wilson (2000), "The Production-Side Approach to Estimating Embodied Technological Change," mimeo.

Solow, Robert M. (1956), "A Contribution to the Theory of Economic Growth," Quarterly Journal of Economics 70 (February), 65-94.

------------- (1962), “Technical Progress, Capital Formation, and Economic Growth," The American Economic Review, Vol. 52, No. 2, Papers and Proceedings of the Seventy-Fourth Annual Meeting of the American Economic Association. May, pp. 76-86. 
Figure 1

Determinants of per capita output

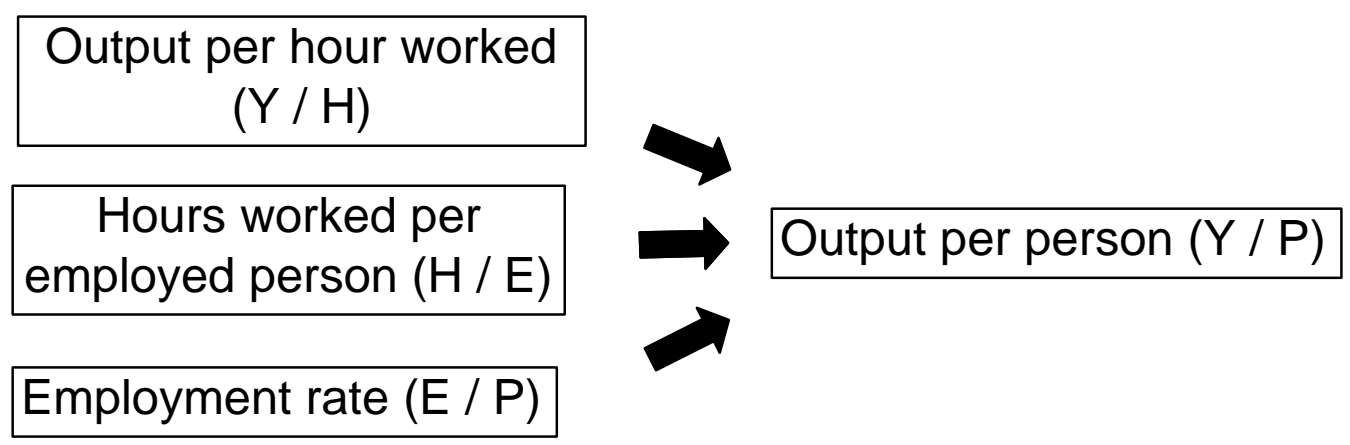




\section{Figure 2}

Existing evidence on the contribution of technical progress to growth in per capita output

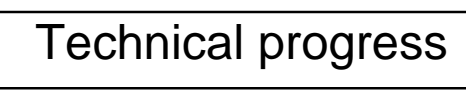

\section{Output per hour worked $(\mathrm{Y} / \mathrm{H})$}

Hours worked per
employed person $(\mathrm{H} / \mathrm{E})$

Employment rate $(\mathrm{E} / \mathrm{P})$
$\Rightarrow$ Output per person (Y/P) 
Figure 3

Hypothesized additional contribution of technical progress to growth in per capita output

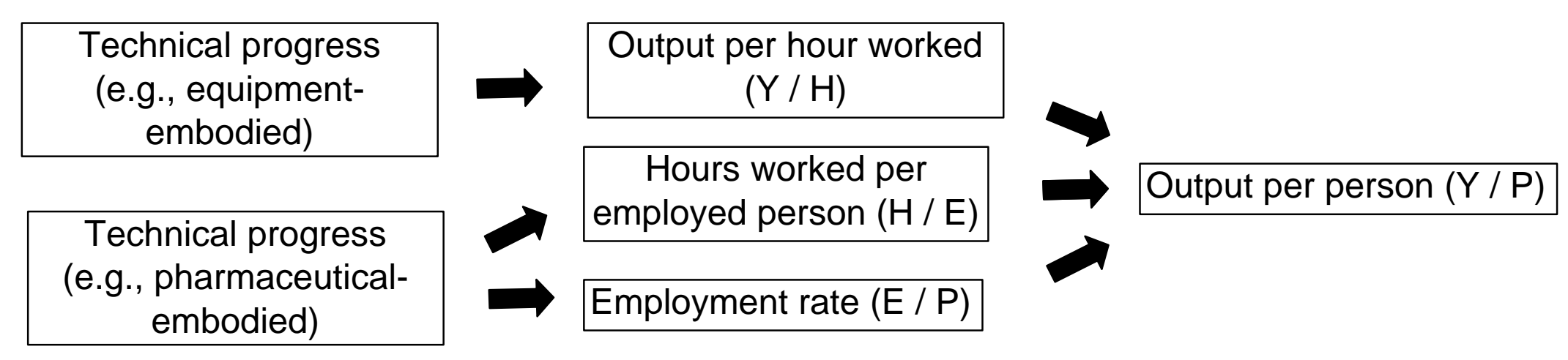


Figure 4

Industrial $R \& D$ funds as a percent of net sales in R\&D-performing companies, 1997

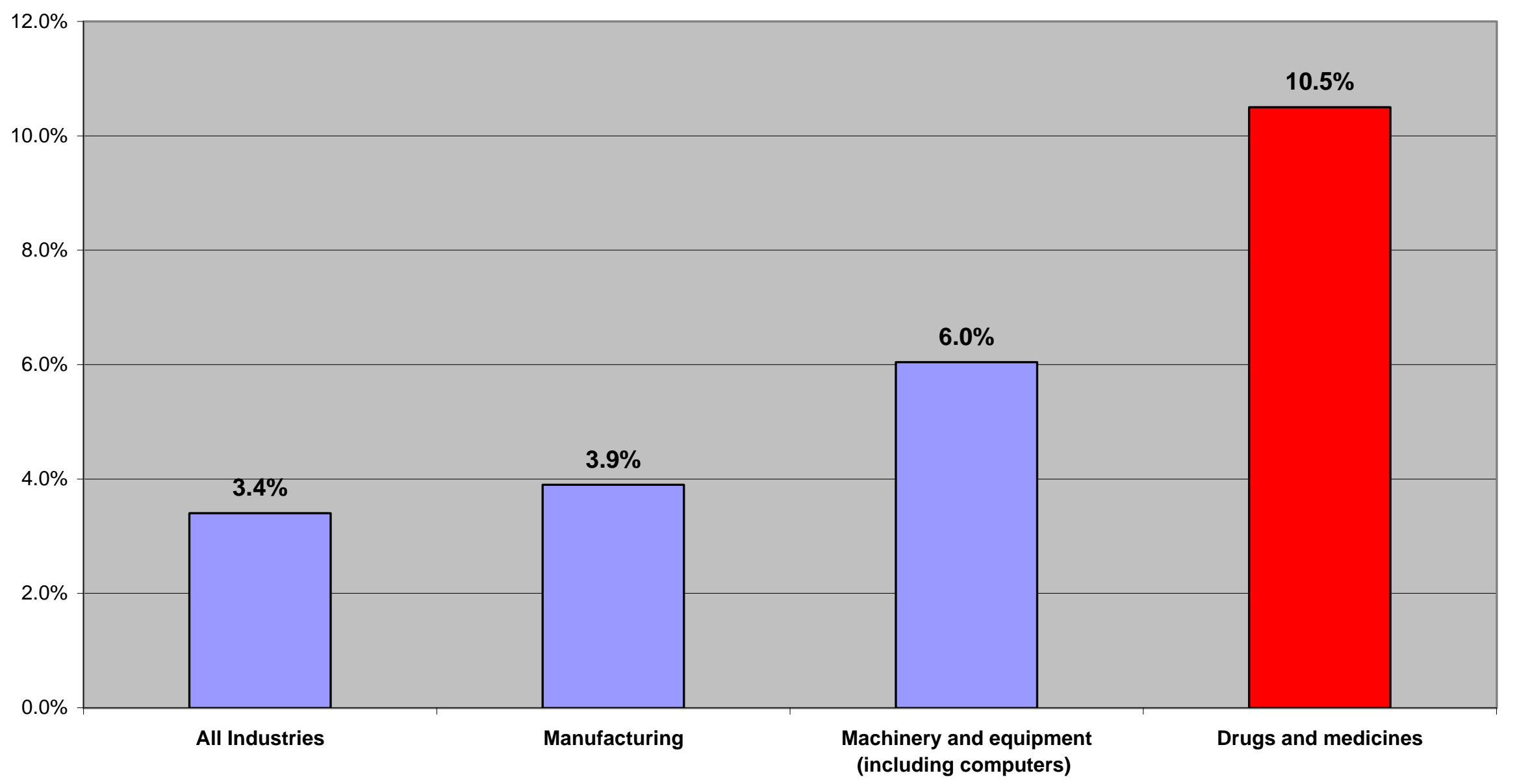

Source: National Science Foundation. 


\section{Figure 5}

Percent of people unable to work, by age

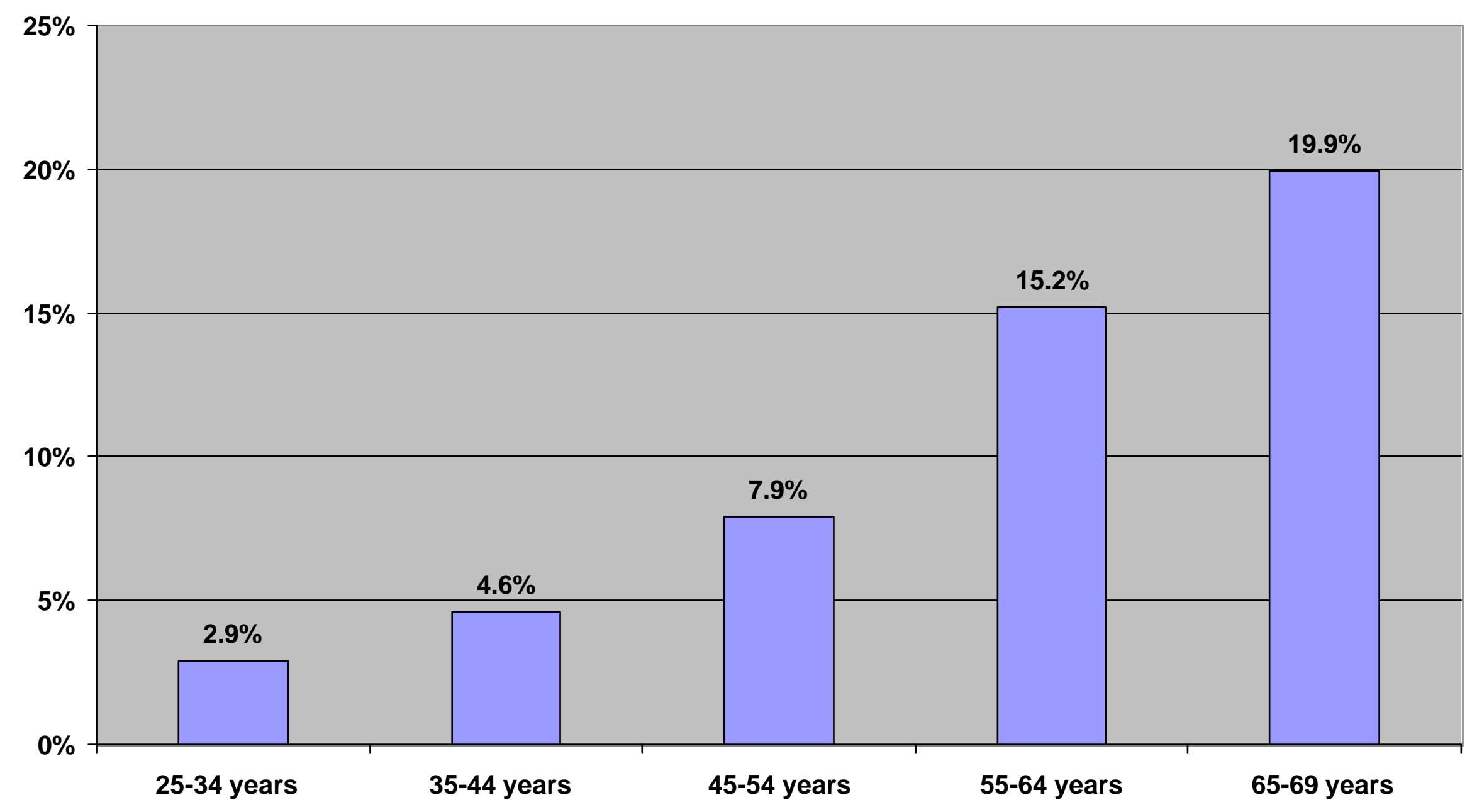

The figures are based on pooled data from 1987-1996 National Health Interview Surveys. 
Figure 6

Potential nonlinearity in the relationship between

drug vintage $(\mathrm{V})$ and activity limitations (L)

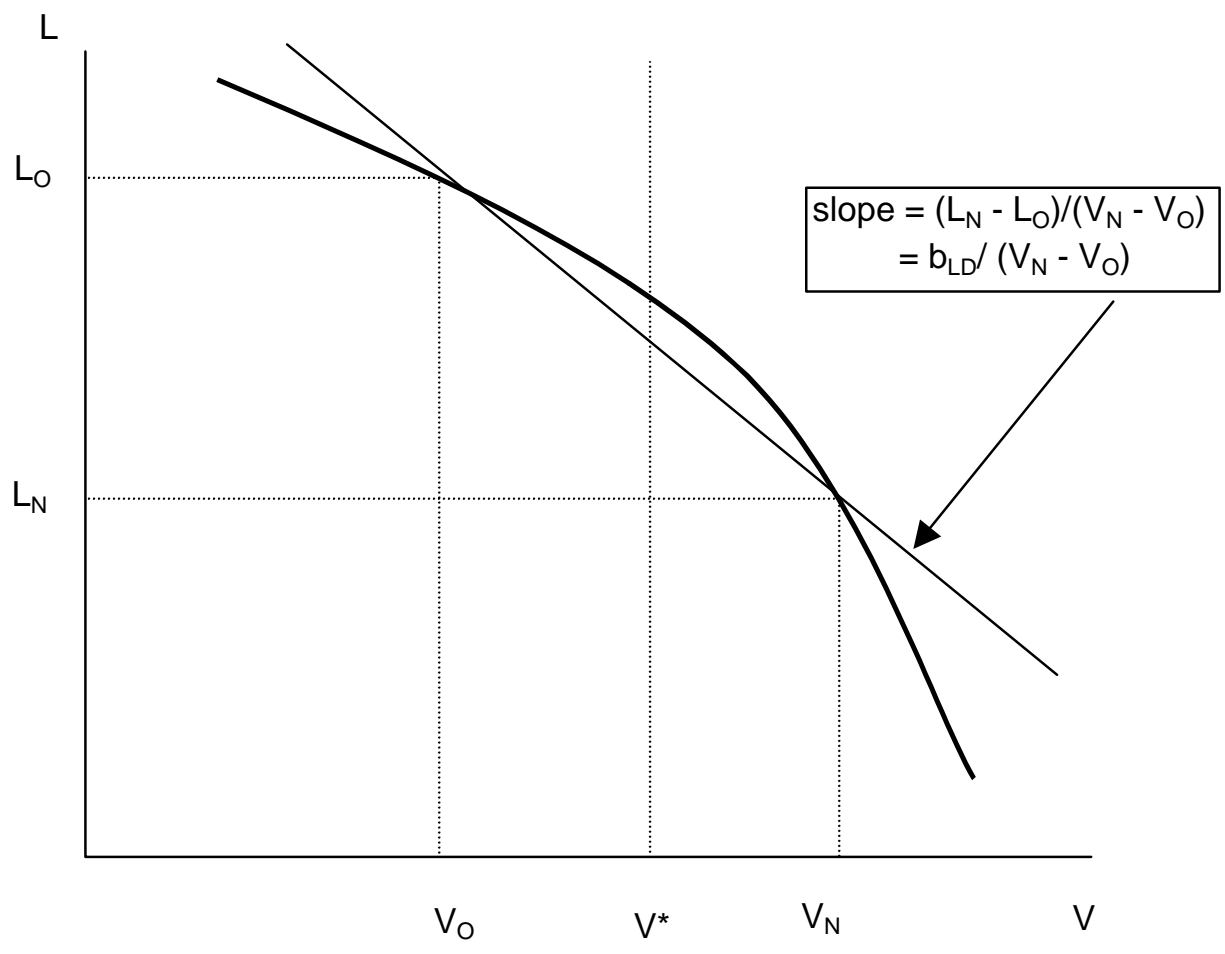


Figure 7

Alternative estimates of the number of new molecular entities approved by the FDA, by year, 1939-1998

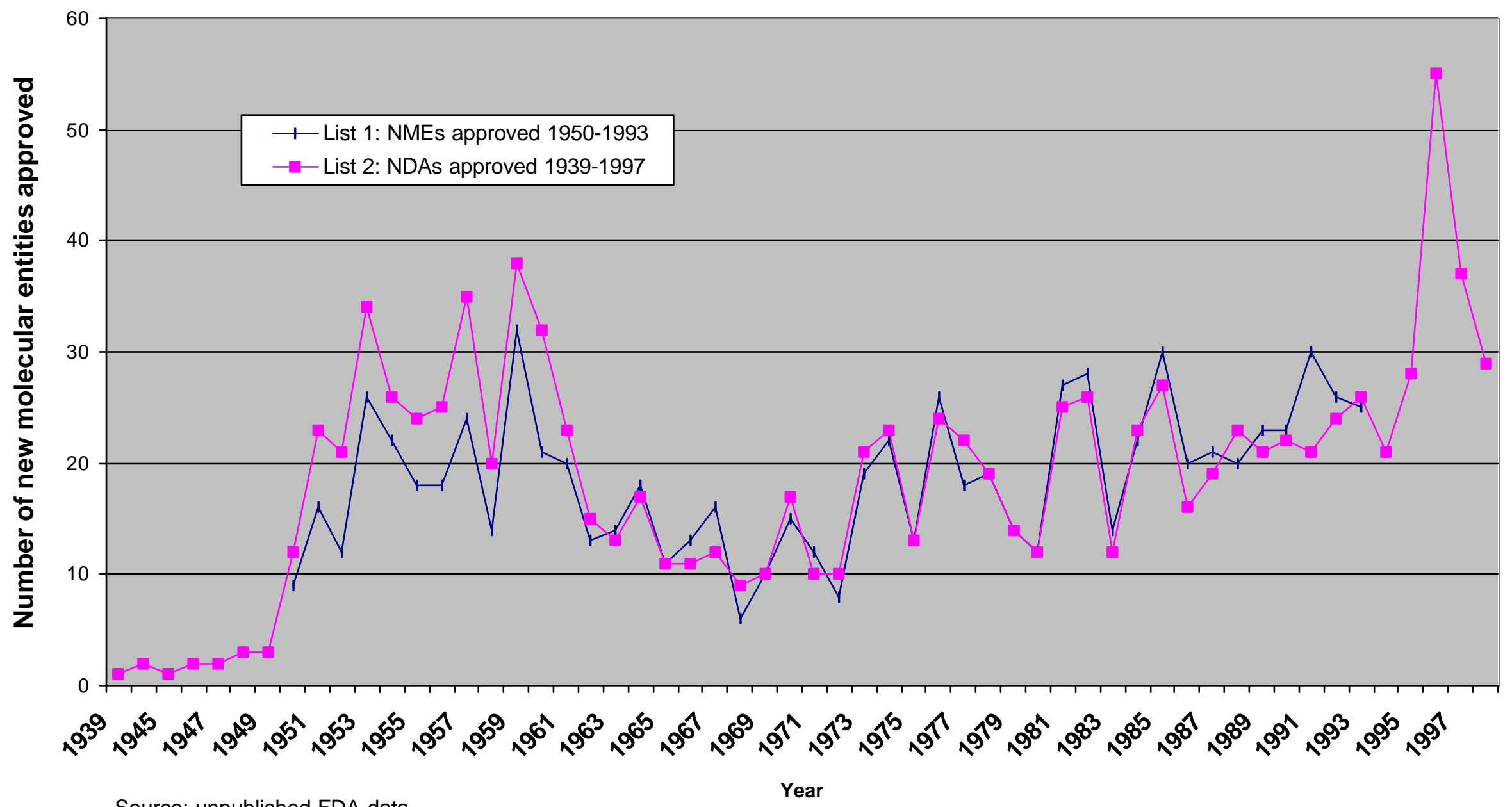

Source: unpublished FDA data. 
Figure 8

Mean vintage of drugs prescribed, 1980-1998

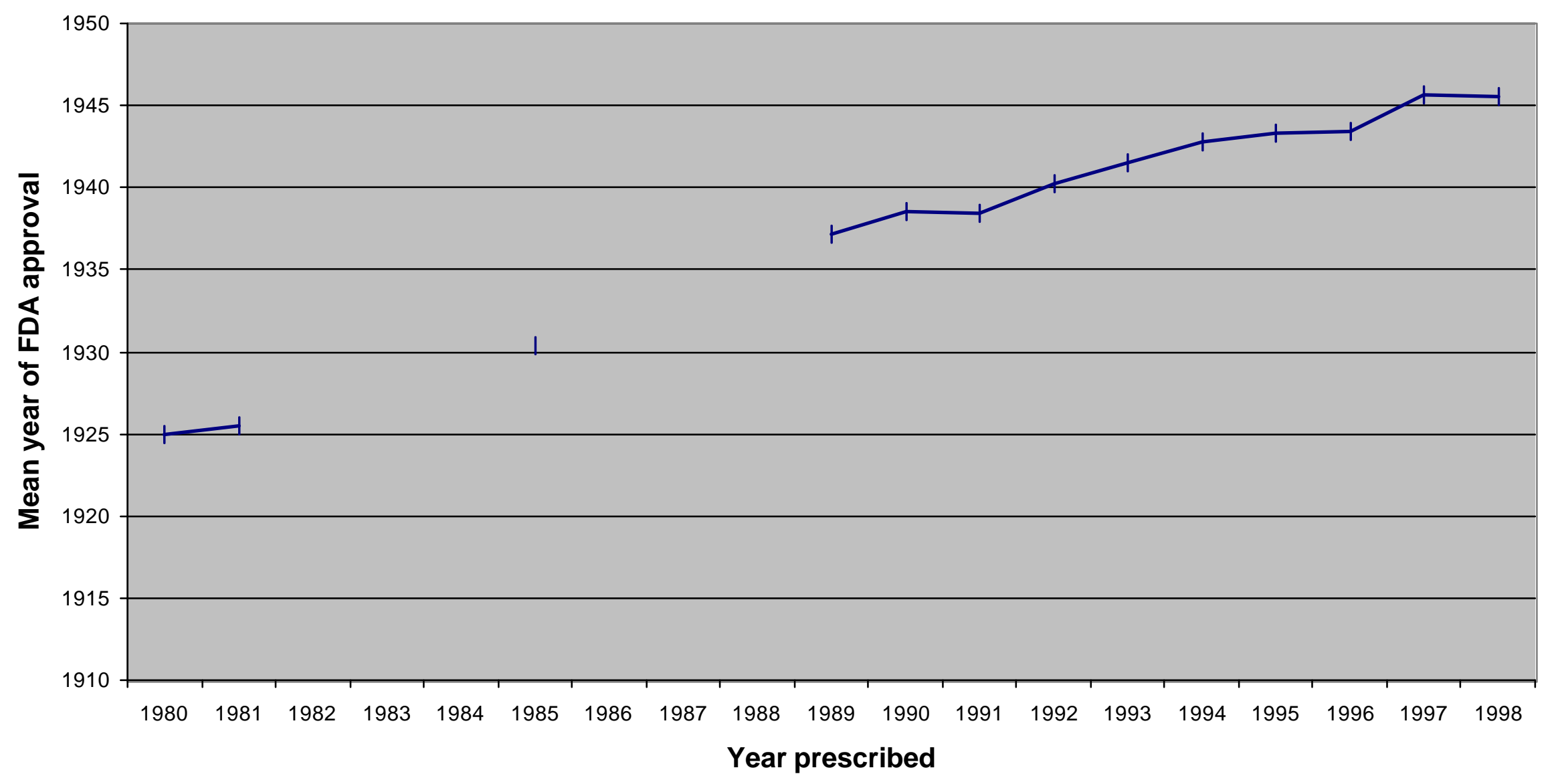

Note: vintage of (pre-1939) drugs with unknown vintages is assumed to be 1900 . 
Figure 9

Fraction of prescriptions that were for drugs approved after given dates, by year, 1980-1998

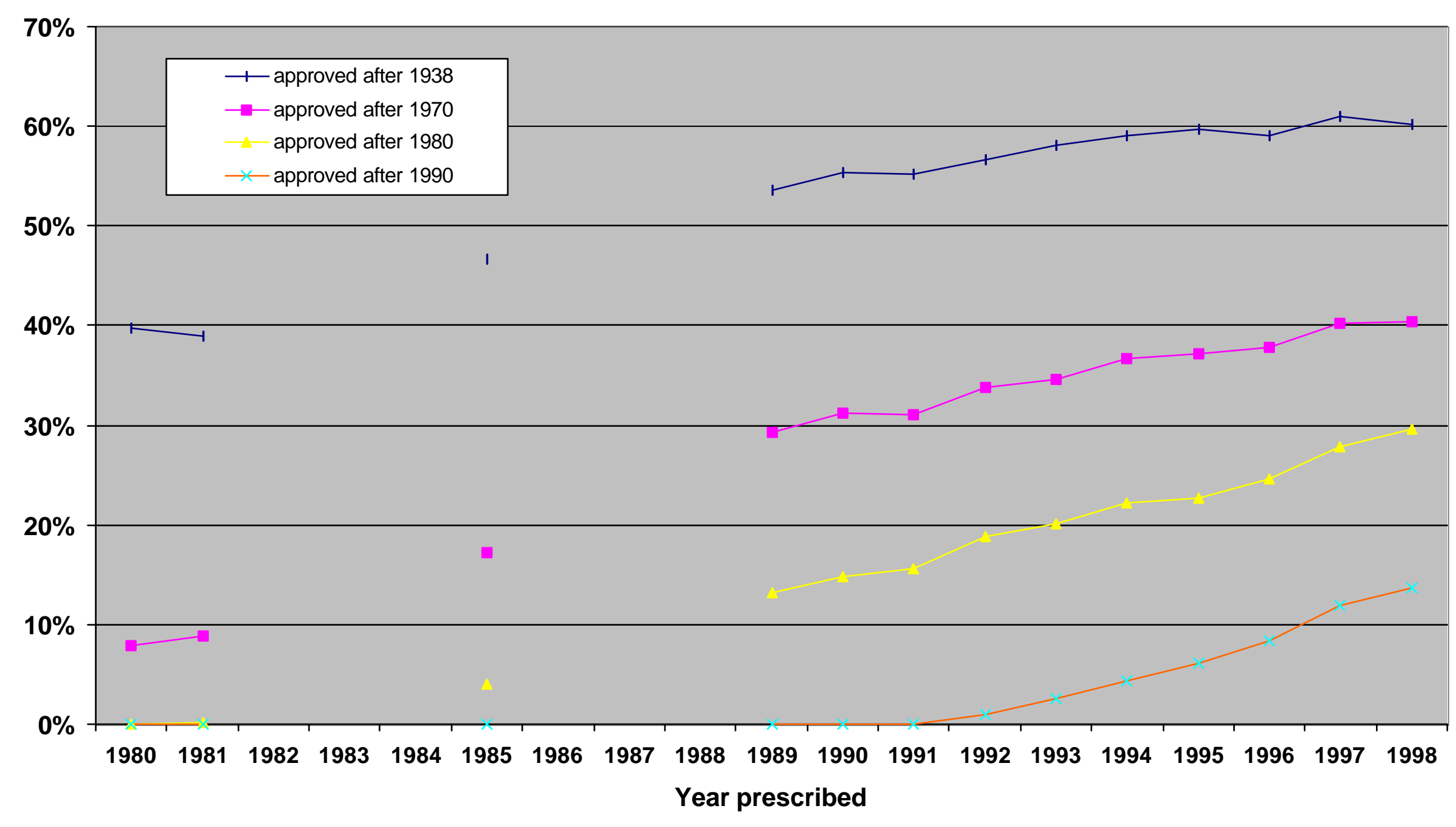


Table 1

Average annual number of occurrences of the 50 most frequent generic substances in drug mentions at office visits: United States, 1994-1996

\begin{tabular}{|c|c|c|}
\hline Rank & \begin{tabular}{|l|} 
Number of \\
occurrences
\end{tabular} & ingredient \\
\hline 1 & 34,834 & AMOXICILLIN \\
\hline 2 & 32,847 & ACETAMINOPHEN \\
\hline 3 & 15,356 & IBUPROFEN \\
\hline 4 & 15,148 & ALBUTEROL \\
\hline 5 & 14,648 & ASPIRIN \\
\hline 6 & 14,530 & HYDROCHLOROTHIAZIDE \\
\hline 7 & 12,157 & FUROSEMIDE \\
\hline 8 & 11,966 & GUAIFENESIN \\
\hline 9 & 11,737 & ESTROGENS \\
\hline 10 & 10,745 & ERYTHROMYCIN \\
\hline 11 & 10,406 & PHENYLEPHRINE \\
\hline 12 & 9,674 & DIGOXIN \\
\hline 13 & 9,461 & LEVOTHYROXINE \\
\hline 14 & 9,159 & PREDNISONE \\
\hline 15 & 9,112 & CODEINE \\
\hline 16 & 9,040 & TRIAMCINOLONE \\
\hline 17 & 8,890 & HYDROCODONE \\
\hline 18 & 8,733 & CEPHALEXIN \\
\hline 19 & 8,659 & PHENYLPROPANOLAMINE \\
\hline 20 & 8,502 & PSEUDOEPHEDRINE \\
\hline 21 & 8,441 & TRIMETHOPRIM \\
\hline 22 & 8,009 & NAPROXEN \\
\hline 23 & 7,890 & NIFEDIPINE \\
\hline 24 & 7,890 & BECLOMETHASONE \\
\hline 25 & 7,888 & DILTIAZEM \\
\hline 26 & 7,736 & SULFAMETHOXAZOLE \\
\hline 27 & 7,514 & RANTIDINE \\
\hline 28 & 7,503 & POTASSIUM REPLACEMENT SOLUTIONS \\
\hline 29 & 7,345 & INSULIN \\
\hline 30 & 7,076 & ENALAPRIL \\
\hline 31 & 6,826 & INFLUENZA VIRUS VACCINE \\
\hline 32 & 6,693 & HYDROCORTISONE \\
\hline 33 & 6,686 & TRIAMTERENE \\
\hline 34 & 6,618 & ESTRADIOL \\
\hline 35 & 6,603 & ATENOLOL \\
\hline 36 & 6,502 & GLYBURIDE \\
\hline 37 & 6,496 & VERAPAMIL \\
\hline 38 & 6,375 & LISINOPRIL \\
\hline 39 & 6,361 & CHLORPHENIRAMINE \\
\hline 40 & 6,256 & FLUOXETINE HYDROCHLORIDE \\
\hline 41 & 6,108 & POLYMIXIN B \\
\hline 42 & 5,925 & ALPRAZOLAM \\
\hline 43 & 5,680 & DEXAMETHASONE \\
\hline 44 & 5,673 & PROPOXYPHENE \\
\hline 45 & 5,670 & MEDROXYPROGESTERONE \\
\hline 46 & 5,667 & LORATADINE \\
\hline 47 & 5,553 & PROMETHAZINE \\
\hline 48 & 5,475 & SERTRALINE \\
\hline 49 & 5,393 & WARFARIN \\
\hline 50 & 5,318 & CLARITHROMYCIN \\
\hline
\end{tabular}



DISEASES OF OTHER ENDOCRINE GLANDS $(250-259)$
HYPERTENSIVE DISEASE $(401-404)$
NEUROTIC DISORDERS, PERSONALITY DISORDERS, AND OTHER NONP...
DISEASES OF ESOPHAGUS, STOMACH, AND DUODENUM $(530-537)$ OTHER METABOLIC DISORDERS OTHER FORMS OF HEART DISEASE (420.429) DISEASES OF OTHER ENDOCRINE GLANDS CHRONIC OBSTRUCTIVE PULMONARY DISEASE AND ALLEDD CONDITUTE DISORDERS OF THE EYE AND ADNEXA (360-379)

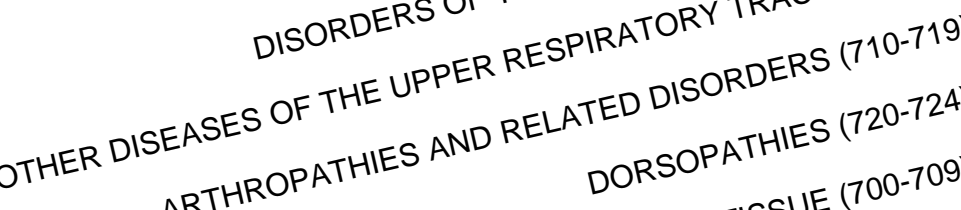
DORSOPATHIES (720-724) OTHER DISEASES OF SKIN AND SUBCUTANEOUS TSS TSORDERS OF THE EYE AND ADNEXA $(360-379)$
DISORDE OTHER INFLAMMATORY CONDITIONS OF SKIN AND SUBCUTANEOUS TISS.
ACUTE RESPIRATORY INFECTIONS (460-466) ACUTE RESPIRATORY TORY CONDITIONROCESS (380-38)
DISEASES OF THE EAR AND MASTOID PRO
OTHER DISORDERS OF FEMALE GENITAL TRACT (617-629)

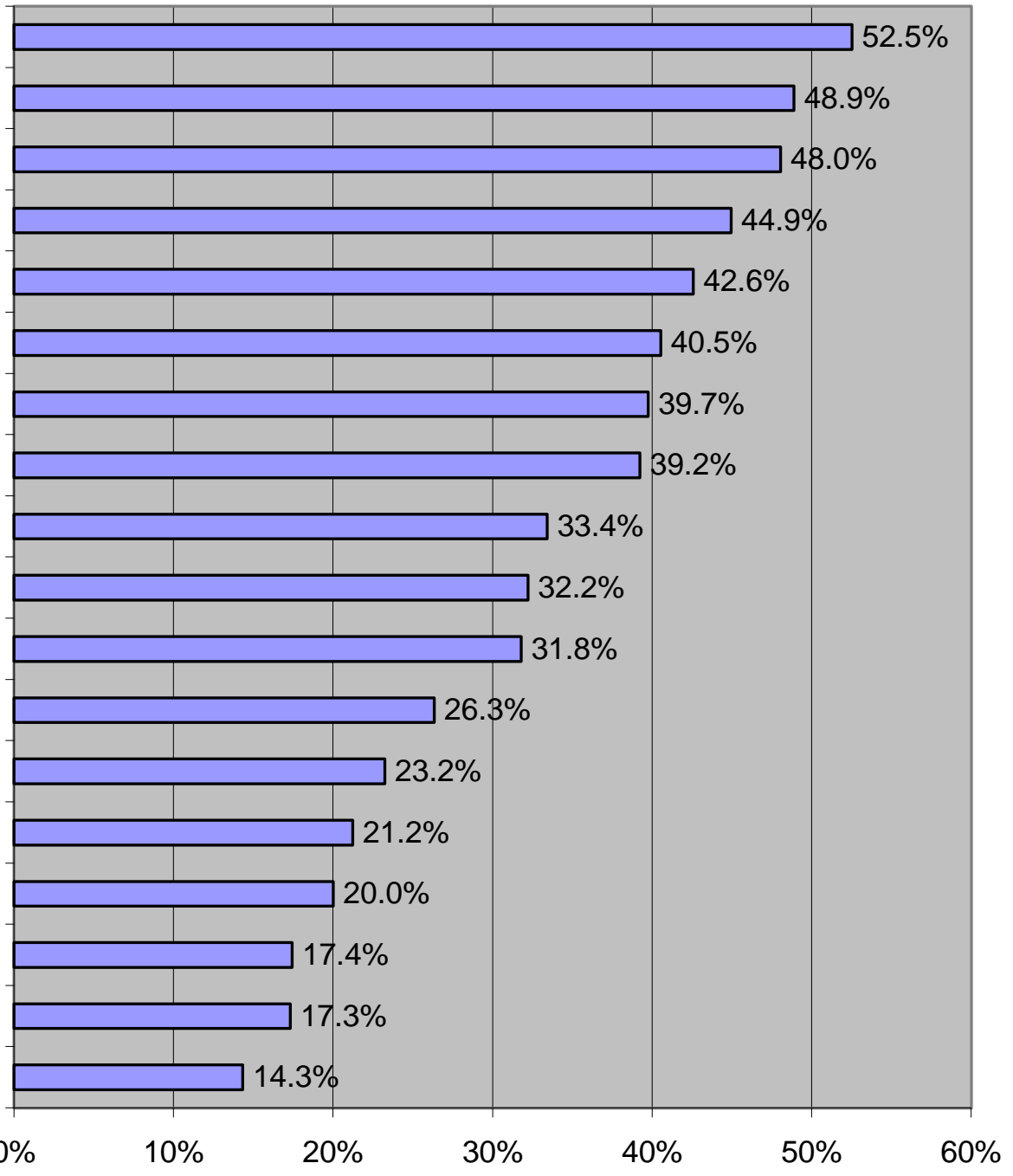

Figure 10

Percent of 1998 prescriptions that were for drugs approved by the FDA after 1980, by condition (conditions with more than $\mathbf{2 0}$ million prescriptions) 
Table 2

Estimates of vintage coefficients from eq. (6):

alternative measures of activity limitation and drug vintage

\begin{tabular}{|l|c|c|c|c|c|}
\hline Column: & 1 & 2 & 3 & 4 & 5 \\
\hline Vintage measure: & V_Mean & post70 & post80 & post85 & post90 \\
\hline
\end{tabular}

Dependent variable: main_act limit $($ mean $=\mathbf{0 . 1 9 8})$

\begin{tabular}{|l|c|c|c|c|c|}
\hline vintage coefficient & -0.00053 & -0.03796 & -0.03492 & -0.05968 & -0.07747 \\
\hline std. err. & 0.00018 & 0.00885 & 0.00831 & 0.0136 & 0.02029 \\
\hline t-stat & -3.03 & -4.29 & -4.2 & -4.39 & -3.82 \\
\hline p-value & 0.0026 & $<.0001$ & $<.0001$ & $<.0001$ & 0.0001 \\
\hline
\end{tabular}

Dependent variable: main_work_limit (mean $=\mathbf{0 . 1 5 2}$ )

\begin{tabular}{|l|c|c|c|c|c|}
\hline vintage coefficient & -0.00038 & -0.03129 & -0.02904 & -0.05094 & -0.06498 \\
\hline std. err. & 0.00016 & 0.00833 & 0.00782 & 0.01279 & 0.01907 \\
\hline t-stat & -2.32 & -3.76 & -3.71 & -3.98 & -3.41 \\
\hline p-value & 0.0206 & 0.0002 & 0.0002 & $<.0001$ & 0.0007 \\
\hline
\end{tabular}

Dependent variable: any work limit (mean $=\mathbf{0 . 2 5 8}$ )

\begin{tabular}{|l|c|c|c|c|c|}
\hline vintage coefficient & -0.00054 & -0.03534 & -0.0367 & -0.0625 & -0.05934 \\
\hline std. err. & 0.00018 & 0.00914 & 0.00855 & 0.01398 & 0.021 \\
\hline t-stat & -3.01 & -3.87 & -4.29 & -4.47 & -2.83 \\
\hline p-value & 0.0028 & 0.0001 & $<.0001$ & $<.0001$ & 0.0049 \\
\hline
\end{tabular}

Dependent variable: unable work $($ mean $=\mathbf{0 . 0 9 5})$

\begin{tabular}{|l|c|c|c|c|c|}
\hline vintage coefficient & -0.00016 & -0.01647 & -0.01546 & -0.03401 & -0.04806 \\
\hline std. err. & 0.00013 & 0.00665 & 0.00624 & 0.01018 & 0.01513 \\
\hline t-stat & -1.23 & -2.48 & -2.48 & -3.34 & -3.18 \\
\hline p-value & 0.2203 & 0.0135 & 0.0135 & 0.0009 & 0.0016 \\
\hline
\end{tabular}

Dependent variable: restricted_days $($ mean $=\mathbf{0 . 8 3 8}$ )

\begin{tabular}{|l|c|c|c|c|c|}
\hline vintage coefficient & -0.00328 & -0.17585 & -0.13504 & -0.25134 & -0.17854 \\
\hline std. err. & 0.00136 & 0.06938 & 0.06523 & 0.10674 & 0.1592 \\
\hline t-stat & -2.41 & -2.53 & -2.07 & -2.35 & -1.12 \\
\hline p-value & 0.0163 & 0.0115 & 0.0389 & 0.0189 & 0.2626 \\
\hline
\end{tabular}


Table 3

Effects of excluding OTC \& combination drugs and controlling for changes in prevalence

\begin{tabular}{|l|c|c|c|}
\hline Column: & 1 & 2 & 3 \\
\hline Vintage measure: & post80 & post80 & post80 \\
\hline OTC \& combination drugs & included & excluded & excluded \\
\hline $\log ($ prevalence $)$ & excluded & excluded & included \\
\hline
\end{tabular}

Dependent variable: main act limit $($ mean $=\mathbf{0 . 1 9 8}$ )

\begin{tabular}{|l|c|c|c|}
\hline vintage coefficient & -0.03492 & -0.02842 & -0.02643 \\
\hline std. err. & 0.00831 & 0.0062 & 0.00626 \\
\hline t-stat & -4.20 & -4.59 & -4.22 \\
\hline p-value & $<.0001$ & $<.0001$ & $<.0001$ \\
\hline
\end{tabular}

Dependent variable: main work limit (mean $=\mathbf{0 . 1 5 2}$ )

\begin{tabular}{|l|c|c|c|}
\hline vintage coefficient & -0.02904 & -0.02587 & -0.02412 \\
\hline std. err. & 0.00782 & 0.0058 & 0.00586 \\
\hline t-stat & -3.71 & -4.46 & -4.12 \\
\hline p-value & 0.0002 & $<.0001$ & $<.0001$ \\
\hline
\end{tabular}

Dependent variable: any work limit $($ mean $=\mathbf{0 . 2 5 8})$

\begin{tabular}{|l|c|c|c|}
\hline vintage coefficient & -0.0367 & -0.03195 & -0.0298 \\
\hline std. err. & 0.00855 & 0.00636 & 0.00643 \\
\hline t-stat & -4.29 & -5.02 & -4.64 \\
\hline p-value & $<.0001$ & $<.0001$ & $<.0001$ \\
\hline
\end{tabular}

Dependent variable: unable work $($ mean $=\mathbf{0 . 0 9 5})$

\begin{tabular}{|l|c|c|c|}
\hline vintage coefficient & -0.01546 & -0.01399 & -0.01279 \\
\hline std. err. & 0.00624 & 0.00469 & 0.00475 \\
\hline t-stat & -2.48 & -2.98 & -2.69 \\
\hline p-value & 0.0135 & 0.003 & 0.0073 \\
\hline
\end{tabular}

Dependent variable: restricted days (mean $=\mathbf{0 . 8 3 8}$ )

\begin{tabular}{|l|c|c|c|}
\hline vintage coefficient & -0.13504 & -0.08221 & -0.08359 \\
\hline std. err. & 0.06523 & 0.05864 & 0.05945 \\
\hline t-stat & -2.07 & -1.40 & -1.41 \\
\hline p-value & 0.0389 & 0.1615 & 0.1602 \\
\hline
\end{tabular}


Table 4

Estimated costs of increase in vintage necessary to achieve reductions in activity limitations

\begin{tabular}{|l|c|c|c|c|c|}
\hline Column: & 1 & 2 & 3 & 4 & 5 \\
\hline Vintage threshold: & 1970 & 1980 & 1985 & 1990 & average \\
\hline
\end{tabular}

\section{Drug prices}

\begin{tabular}{|l|r|r|r|r|}
\hline \hline $\mathrm{P}_{\mathrm{N}}$ & $\$ 52.35$ & $\$ 59.08$ & $\$ 65.54$ & $\$ 65.15$ \\
\hline $\mathrm{P}_{\mathrm{O}}$ & $\$ 26.09$ & $\$ 26.66$ & $\$ 29.61$ & $\$ 32.38$ \\
\hline $\mathrm{P}_{\mathrm{N}}-\mathrm{P}_{\mathrm{O}}$ & $\$ 26.26$ & $\$ 32.42$ & $\$ 35.92$ & $\$ 32.76$ \\
\hline
\end{tabular}

\section{vintage coefficients}

\begin{tabular}{|l|c|c|c|c|}
\hline \hline main_act_limit & -0.038 & -0.035 & -0.060 & -0.077 \\
\hline main_work_limit & -0.031 & -0.029 & -0.051 & -0.065 \\
\hline any_work_limit & -0.035 & -0.037 & -0.062 & -0.059 \\
\hline unable_work & -0.016 & -0.015 & -0.034 & -0.048 \\
\hline $\begin{array}{l}\text { restricted_days } \\
\text { (annualized) }\end{array}$ & -1.742 & -1.337 & -2.489 & -1.768 \\
\hline
\end{tabular}

"Upper-bound cost estimates": $\mathbf{P}_{\mathrm{V}} /$-(vintage coefficient)

\begin{tabular}{|l|r|r|r|r|r|}
\hline main_act_limit & $\$ 1,379$ & $\$ 1,692$ & $\$ 1,098$ & $\$ 841$ & $\$ 1,252$ \\
\hline main_work_limit & $\$ 1,673$ & $\$ 2,034$ & $\$ 1,287$ & $\$ 1,003$ & $\$ 1,499$ \\
\hline any_work_limit & $\$ 1,481$ & $\$ 1,610$ & $\$ 1,049$ & $\$ 1,098$ & $\$ 1,309$ \\
\hline unable_work & $\$ 3,178$ & $\$ 3,820$ & $\$ 1,927$ & $\$ 1,356$ & $\$ 2,570$ \\
\hline $\begin{array}{l}\text { restricted_days } \\
\text { (annualized) }\end{array}$ & $\$ 30$ & $\$ 44$ & $\$ 26$ & $\$ 37$ & $\$ 34$ \\
\hline
\end{tabular}

"Lower-bound cost estimates": $\left(\mathbf{P}_{\mathbf{N}}-\mathbf{P}_{\mathbf{0}}\right) /-($ vintage coefficient $)$

\begin{tabular}{|l|r|r|r|r|r|}
\hline \hline main_act_limit & $\$ 692$ & $\$ 928$ & $\$ 602$ & $\$ 423$ & $\$ 661$ \\
\hline main_work_limit & $\$ 839$ & $\$ 1,116$ & $\$ 705$ & $\$ 504$ & $\$ 791$ \\
\hline any_work_limit & $\$ 743$ & $\$ 883$ & $\$ 575$ & $\$ 552$ & $\$ 688$ \\
\hline unable_work & $\$ 1,594$ & $\$ 2,096$ & $\$ 1,056$ & $\$ 682$ & $\$ 1,357$ \\
\hline $\begin{array}{l}\text { restricted_days } \\
\text { (annualized) }\end{array}$ & $\$ 15$ & $\$ 24$ & $\$ 14$ & $\$ 19$ & $\$ 18$ \\
\hline
\end{tabular}

